\title{
Variables That Predict Burnout Among Sex Offender Treatment Providers: Work Setting, Gender, Work Hours
}

Jennifer Pravlik

West Virginia University

Follow this and additional works at: https://researchrepository.wvu.edu/etd

\section{Recommended Citation}

Pravlik, Jennifer, "Variables That Predict Burnout Among Sex Offender Treatment Providers: Work Setting, Gender, Work Hours" (2012). Graduate Theses, Dissertations, and Problem Reports. 353.

https://researchrepository.wvu.edu/etd/353

This Dissertation is protected by copyright and/or related rights. It has been brought to you by the The Research Repository @ WVU with permission from the rights-holder(s). You are free to use this Dissertation in any way that is permitted by the copyright and related rights legislation that applies to your use. For other uses you must obtain permission from the rights-holder(s) directly, unless additional rights are indicated by a Creative Commons license in the record and/ or on the work itself. This Dissertation has been accepted for inclusion in WVU Graduate Theses, Dissertations, and Problem Reports collection by an authorized administrator of The Research Repository @ WVU.

For more information, please contact researchrepository@mail.wvu.edu. 
Variables That Predict Burnout Among Sex Offender Treatment Providers:

Work Setting, Gender, Work Hours

Jennifer Pravlik

Dissertation submitted to the College of Human Resources and Education

at West Virginia University

in partial fulfillment of the requirements

for the degree of

Doctor of Philosophy

in

Counseling Psychology

Roy Tunick, Ed.D., Chair

James Bartee, Ph.D.

Jeffrey Daniels, Ph.D.

Ed Jacobs, Ph.D.

Sebastian Diáz, Ph.D.

Department of Counseling, Rehabilitation Counseling,

$\&$ Counseling Psychology

Morgantown, West Virginia

2012

Keywords: Burnout, sex offenders, vicarious trauma

Copyright (@ Jennifer Pravlik, 2012 


\begin{abstract}
Variables That Predict Burnout Among Sex Offender Treatment Providers:

Work Setting, Gender, Work Hours

Jennifer Pravlik
\end{abstract}

Psychological treatment of the sexual offender population continues to be an arduous task for therapists. There is evidence that many therapists will experience burnout at some point during their careers. Providing treatment in a burned out state can cause harm to the therapist, client, and community (Barnett, Baker, Elman, \& Schoener, 2007). It is necessary to determine the variables that influence burnout in order to increase awareness and to address the variables at an organization and personal level in order to identify therapists that may be at risk of burnout. In this I study examined the relationship of variables identified through literature and the influence each variable has on the development of burnout. The variables are gender, current age, level of training, years of experience, theoretical orientation, supervision, percentage of sex offenders on caseload, individual or group therapy and primary work setting. Of the 210 ATSA listserv members that responded to this study, one hundred fifty one participants were used in the analysis. It was determined through the use of CHAID analyses that the most significant variable that predicted burnout was work setting, specifically prison/correctional settings and outpatient setting. The information gained from this study will assist in increasing awareness of burnout which in turn may lead to the implementation of interventions for prevention (Wicks, 2008). 


\section{DEDICATION}

This dissertation is dedicated to my husband, my parents, and my church family. Without the support, love, and prayers, this would have not been possible; "With God all things are possible" (Matt. 19:26). Thank you for your unending dedication to me and all the "little things" you did to provide me with the strength and perseverance to complete this project. This dissertation is also completed in the memory of Amy Wentworth and her daughter Holly. You were the perfect friend and an angel in my life. Your love and wisdom has followed with me even after you were no longer with me on this Earth. Grandma Lytle, the memory of the pride I saw on your face when I told you that I was going for my Ph.D. reminded me many times to keep on going. You were a fighter, so I fought also! 


\section{ACKNOWLEDGEMENTS}

I must first acknowledge that the completion of this degree is a gift from God. Without faith, I would not have been able to persevere. God had allowed for many changes and challenges that allowed the right people at the right time to be a part of my life and this process over the last few years. I have learned so much about research, statistics, but most importantly about myself. I can only hope and pray that I will use this degree in the way God has planned for me.

To Charles, my husband, your strength and support carried me so many times. You are my DI.

To my parents, words cannot express the gratitude I have for everything you have provided throughout my life to make this all happen. Mom, you taught me to be independent yet not so independent to not ask for help when needed. You taught me patience and you always try to keep me level headed. Dad, you taught me to work hard, no matter what got in the way. You also taught me that with hard work, you can learn and do anything you want.

To my Aunt Mary and Uncle Darwin, I thank you for your prayers, late dinners and long conversations. They were needed and appreciated more than words can say.

To my friends, Lisa, Barb, Emily, Sharon, and Remona, you have given me the boost whenever I needed. Thank you for listening to all the B and M. You are all my favorite sweet tarts!

To the Gospel Alliance Church Family, your quiet support, your loud prayers, and your unconditional love helped me feel peace and joy in the most difficult times.

To Jacque Strait, my friend and cohort member, and Jon Glass, internship buddy, the two of you have been awesome in your support and statistical knowledge. I appreciate you and the time you spent working with me to understand the simplest of things (like the difference between dependent and independent variables).

To Dr. Roy Tunick, my dissertation chair, you took me on late in the game, and provided me with the strength, support and direction at a time when I thought all was lost. I will never be able to tell you how much I appreciate your diligence, quick and constructive feedback, and your willingness to go out on a limb to make sure I was successful. It is people like you that work behind the scenes to make folks like me succeed. My gratitude is unending as you are a gift from God.

To my dissertation committee, Dr. Bartee, Dr. Daniels, Dr. Jacobs, and Dr. Diáz, thank you for taking the time to be a part of my committee. Your time and commitment is greatly appreciated. Dr. Bartee, as always you find a way to make everything okay. 


\section{TABLE OF CONTENTS}

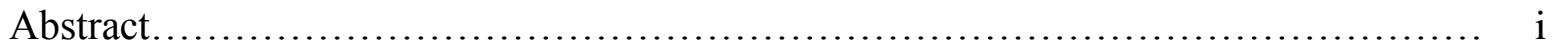

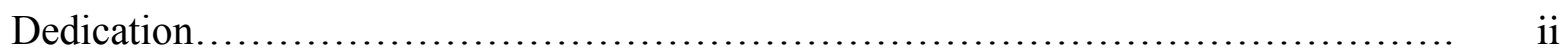

Acknowledgements.....................................................

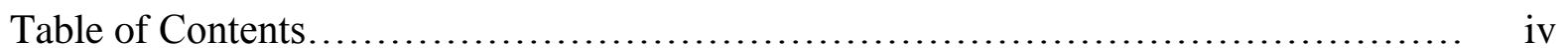

List of Tables............................................................. vi

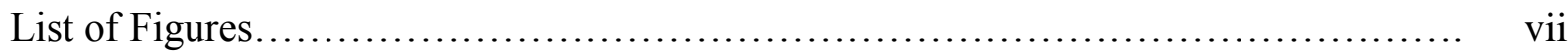

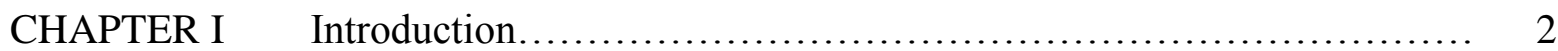

Literature Review.......................................... 7

Burnout........................................................ 7

Causal Factors.......................................... 8

Experience of Burnout....................................... 14

Ethical Considerations.................................... 21

Therapists Working with Sex Offenders........................ 22

Factors Influencing Burnout in Therapists................... 22

Influence of Work Place Environment...................... 32

Factors Specific to Working with Sex Offenders................. 38

Summary............................................... 40

Definition of Terms.......................................... 42

CHAPTER II $\quad$ Method........................................................... 44

Participants.................................................. 44

Design.................................................. 45

Measures................................................... 46 
Demographic and Work Questionnaire....................... 47

Maslach Burnout Inventory................................. 47

Data Collection.............................................. 48

Data Analysis................................................ 49

Hypothesis................................................ 51

CHAPTER III $\quad$ Results................................................... 54

Data Summary......................................... 54

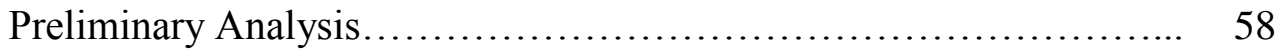

Primary Analysis........................................... 60

CHAPTER IV Discussion................................................. 69

Limitations of Study .......................................... 73

Implications of Training and Practice......................... 76

Recommendations for Future Research....................... 79

Conclusion.................................................. 80

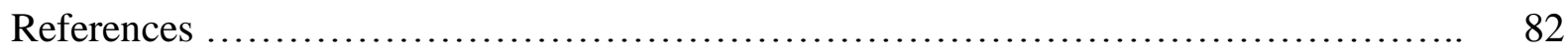

Appendices............................................................ 95 
BURNOUT AMONG SEX OFFENDER TREATMENT PROVIDERS

\section{LIST OF TABLES}

Table 1: Variables used in the CHAID Analysis................................ 55

Table 2: MBI normative subscale means and Standard Deviations.................. 59

Table 3: Current sample subscale means and standard Deviations.................. 60

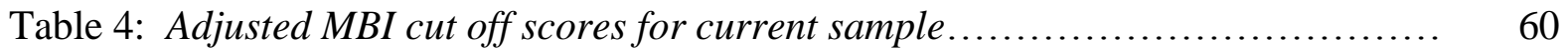




\section{LIST of FIGURES}

Figure 1: Classification tree for burnout................................... 64

Figure 2: Classification tree for personal accomplishment $\ldots \ldots \ldots \ldots \ldots \ldots \ldots \ldots \ldots \ldots .65$

Figure 3: Classification tree for emotional exhaustion.......................... 66

Figure 4: Classification tree for depersonalization.............................. 67 


\section{Chapter I Introduction and Review of Literature}

Psychologists are bound by ethical principles that provide guidance and standards in professional practices (APA, 2010). A number of these guidelines and standards specifically address working in an impaired state. The Ethical Principles of Psychologists and Code of Conduct, Standard 2.06: Personal Problems and Conflicts, indicates that psychologists are to "refrain from initiating an activity when they know or should know that there is a substantial likelihood that their personal problems will prevent them from performing their work-related activities in a competent manner" (APA, 2010, p. 5). The General Principle A: Beneficence and Non-maleficence states "psychologists strive to be aware of the possible effect of their own physical and mental health on their ability to help those with whom they work" (APA, 2010, p. 2). Working with clients in an impaired state can lead to harm of clients, communities, and the therapists themselves. Burnout, a physical, mental and emotional exhaustion, could potentially lead to impaired practice (Barnett, Baker, Elman, \& Schoener, 2007).

One-third of psychologists report experiencing distress and symptoms of burnout at some point in their career (Barnett, et al., 2007). Historically, clinicians in the helping profession average ten years of effective work with clients because of stress, work place issues, and transference/countertransference issues, all of which may contribute to the development of burnout (Grosch \& Olsen, 1994). Although it may occur at any point in a career, 65 to 75 percent of helping professionals will experience burnout in the first three to five years of their careers (Cherniss, 1980; Masters, R.E., 2004). With a research sample of 6,720 licensed or certified behavioral health providers, it was found that approximately $13 \%$ were at high risk for burnout (Sprang, Clark, \& Whitt-Woosley, 2007). In addition, this condition does not just 
affect the individual (e.g. Maslach, 2001), but also affects family members and clients (Kahill, 1988). The effects become evident in major life domains, such as career, finances, and relationships, to name a few.

There are many different factors that may lead to this condition that have been described in detail (Sprang, et al., 2007). It can be challenging for therapists to learn to identify and manage burnout symptoms (Kramen-Kahn, 1998; Maslach, 1993). Working in a profession dealing with client problems inevitably brings out multifaceted feelings of fear, anger, disappointment, and even embarrassment, especially since the treatment and solutions may not always be clear cut. Constantly dealing with challenging client circumstances can lead to chronic stress, draining emotional reserves and then burnout (Hyphantis \& Mavreas, 2005; Kraus, 2005; Maslach, Jackson, \& Leiter, 1997).

The management of day to day challenges, such as caseload, schedule, and paperwork, can also result in emotional distress, vicarious trauma, and therapist impairment. All of these can also result in an inability to provide competent client care (Barnett, et al., 2007; Ross, Altmaier, \& Russell, 1989; Way, VanDeusen, \& Cottrell, 2009).

Although therapists are traditionally trained to deal with the problems of others, they are not always exposed to training that can aid in identifying and dealing with personal stress reactions resulting from treating the problems of others (Devilly, Wright, \& Varker, 2009; Emerson \& Markos, 1996). As a result of this lack of training, some therapists may experience difficulty. Examples include the use of maladaptive coping mechanisms, such as drugs and alcohol or isolation (Maslach, 1997) and/or the development of mental health issues including anxiety and depression (Hallsten, 1993; Kahill, 1988; Maslach, Schaufeli, \& Leiter, 2001). 
If the professional ineffectively manages these challenges, there is a much greater risk of burnout and its resulting negative effects, such as increased time at work and decreased time for family functions, increased irritability at home, and other relationship problems (Barnett, et al., 2007). Furthermore, the client is at greater risk for a decrease in the quality of care (Emerson \& Markos; 1996, Kottler \& Hazler, 1996), thus limiting the opportunity to achieve change in therapy (Blanchard, 1998; Maslach, 1982, 1993; Maslach, et al., 2001). When one professional is unable to provide effective treatment, there is also greater potential for negative community perceptions that could further generalize to the entire profession.

Researchers have determined that therapists working with sex offenders are placed in more stressful situations than those who do not work with sex offenders (Leicht, 2008). These therapists experience unique challenges, in addition to many of the problems already faced by other helping professionals. These challenges will range in severity and complexity depending on the needs of the client. One challenge specific to those who treat sex offenders is the controversy that stems from the cost and length of treatment compared with the evidence of high recidivism rates (Craig, Browne, \& Stringer, 2003). Even with these possibly incongruent factors in mind, a great deal is expected of therapists, as one outcome of therapy with sex offenders is the hope that communities will emerge safer (Blanchard, 1998).

Professionals working with sex offenders have also identified an increase in countertransference (the emotional reaction a therapist has in reference to the problems a client presents) issues (Strasburger, 2001), vicarious trauma and stigmatization surrounding this work (Leicht, 2008) compared to other therapists working with different populations. Countertransference can have an emotional, psychological, and social impact on the professional as he/she attempts to remain compassionate and understanding in the therapy 
setting (Enzmann, 2005; Maslach, 1982; Zapf, Seifert, Schmutte, Mertini, \& Holtz, 2001). Despite these possible conflicts, both clients and communities expect the therapist to work through these issues without allowing them to negatively impact the therapeutic process.

Another challenge therapists face is the problem of dealing with difficult client behaviors. Many clients, including sex offenders, can be resistant to treatment or may become aggressive in the therapeutic relationship (Clarke \& Roger, 2002). In addition, clients may exhibit self-injurious behaviors, or may have suicidal or homicidal ideation, gestures, or plans. All of these behaviors can have a serious impact on the personal and professional well-being of the clinician. Researchers studying 562 licensed doctoral level psychologists found that negative client behaviors increased levels of emotional exhaustion and depersonalization among the professional participants (Ackerly, Burnell, Holder, \& Kurdek, 1988). Emotional exhaustion and depersonalization are two of three scales used to identify helping professional burnout on the Maslach Burnout Inventory (MBI) (Gabassi, Cervai, Rozbowsky, Semeraro, \& Gregori, 2002; Maslach, et al., 1996). It was found that an increase in levels of depersonalization and emotional exhaustion directly correlate with an increased potential for burnout (Gabassi, et al., 2002; Maslach et al., 1996).

Professionals not only experience stress as a direct result of working with clients (Devilly, et al., 2009), but may also experience stress as a result of indirect factors. Therapists must follow strict rules and regulations established on federal, state, local and organizational levels (Acker, 2003; Clarke \& Roger, 2002). On the federal level, a therapist must understand and be held legally accountable to the Health Information Portability and Accountability Act (HIPAA), Occupational Safety and Health Administration (OSHA), confidentiality laws, as well as others. Each profession has its own state and national governing body with a legally 
binding professional code of ethics (American Psychological Association, 2010; Association for the Treatment of Sexual Abusers, 2001). Issues involved with practice in a particular state include professional licensure requirements, continuing education requirements, and rules regarding the reporting of child abuse. If these are not adhered to, professionals are at risk of losing their licenses to practice, monetary fines, and even litigation.

This research project will identify and discuss the variables affecting burnout in therapists who work with sexual offenders. This project will also strive to produce a dendogram (classification tree) displaying the relative importance of statistically significant independent variables on the dependent variable, which is therapist degree of burnout.

The information gained from this study may help to identify those factors that have the most significant impact on therapist burnout. As a result it is hoped that helping professionals will be better able to take precautions and make necessary changes to prevent and cope with burnout. Organizations and therapists will be able to take precautions by making organizational policies and/or develop personal self care to decrease the risk and impact of this phenomenon. The prevention of this condition in therapists working with sex offenders is extremely important (Barnett, et al., 2007; Kadambi \& Truscott, 2006). Identification of variables that increase burnout levels is an important factor in making the needed changes to protect the profession in order to maintain positive and effective treatment (Shelby, Stoddert, \& Taylor, 2001). The ethical codes of both the American Psychological Association (APA, 2010) and the Association for the Treatment of Sexual Abusers (ATSA, 2001) state that a therapist is not to conduct therapy if impaired in any way. A thorough review of the literature on burnout suggests a positive correlation between the level of burnout and impairment in the provision of 
service delivery. Continued research on this phenomenon should lead to more effective prevention strategies and interventions (Wicks, 2008).

\section{Literature Review}

In the literature review that follows, I will discuss the relationship between the independent variables and effects on their relationship to burnout and the three dimensions of burnout: emotional exhaustion, depersonalization and reduced personal accomplishment. The independent variables identified consistently throughout the literature that will be discussed are: gender, training, supervision, and type of work environment (Maslach, et al., 1996).

\section{Defining Burnout}

Literature on burnout dates back about 40 years, beginning in the mid-1970's with researchers Herbert Freudenberger (1974) and Christina Maslach (1982). Freudenberger was the first to use the term in the literature (Maslach, 1986), although it was not a new concept. He explored both physical and behavioral signs of this phenomenon. During the 1970's and the 1980 's research in the field focused primarily on occupational settings. These studies aimed to achieve a conceptual definition (Burisch, 1993) and promote prevention of the problem. Maslach (1982) initially defined burnout as a syndrome with three elements: emotional exhaustion, depersonalization, and reduced personal accomplishment. It was believed that it was caused by working with people who "are troubled or having problems" (p. 3) and differed from any other type of job stress (Maslach, 1982). This was just the first of many definitions.

Researchers have continued to struggle to develop a formal definition for this phenomenon. Some have stated that defining burnout "is like defining the exact boundaries of a large cloud" (Burisch, 1993, p. 76), that it is a slow process, as if "under a slow boil" (Hobfoll 
\& Freedy 1993, p. 117), or that it has certain gestalt qualities likely to be a little different for each perceiver (Burisch, 1993). In other words, it manifests differently in every person. Each person may exhibit different symptoms and a different intensity of symptoms (Freudenberger, 1974).

There have been attempts to define this construct in various ways, as a unidimensional model, a multidimensional model, conceptual model, mediation model, developmental model, social-exchange model, and conservation of resources model. Others have attempted to represent burnout by describing the emotional, physical, psychological, and behavioral symptoms that appear to be related to this syndrome. This section includes descriptions of each of the models as well as a description of resulting symptoms.

Causal factors. Cox, Kuk, and Leiter (1993) postulated a difference between the unidimensional and multidimensional models of burnout. Unidimensional models define burnout by placing all symptoms within a single construct and excluding different factors: "The whole is greater than the sum of its parts" (p. 180). It is believed that emotional exhaustion and depersonalization are part of the same psychological state, and thus represent the defining feature. On the other hand, multidimensional models define burnout as a construct including different factors and postulate that each factor consists of different symptoms: "The whole is the sum of its parts" (p. 180). In this model, it is believed that a person who is burned out will exhibit symptoms of emotional exhaustion, depersonalization and a reduction in personal accomplishment.

Unidimensional model. The unidimensional model of burnout, which was developed by Ayala Pines and her colleagues, began by defining tedium as a state of physical, mental, and emotional exhaustion that is caused by long-term involvement in emotionally demanding 
situations (Pines, 1997; Schaufel, Bakker, Hoogduin, Schaap, \& Kladler, 2001). In this model tedium is equal to burnout. Through the examination of case studies and clinical experiences, these researchers conceptualized a list of symptoms that includes helplessness, hopelessness, physical fatigue, and low self-esteem (Shirom \& Ezrachi, 2003). These symptoms were then used to develop the Burnout Measure (BM). This measure has been researched in many professional occupations and in a number of different countries, yet its discriminant validity to separate burnout from depression and anxiety has yet to be established (Shirom \& Ezrachi, 2003). The BM also lacks empirical evidence for the set cut-off points in the identification of burnout (Schaufeli, et al., 2001). Through research, this model was identified to be multidimensional, instead of the unidimensional one that was initially claimed (Schaufeli, et al, 2001).

Conceptual model. A conceptual model was described in Maslach and Goldberg's (1998) research on burnout prevention. The concept was described in this study as a response to prolonged work-related emotional and interpersonal stressors, to include the experience of individuals faced with these stressors (Maslach \& Goldberg, 1998). The study of this model specifically analyzed a number of links between the job and the professional. It also examines how professional situations play a role in the potential for emotional exhaustion as well as in levels of personal accomplishment. It also provided researchers with a clearer look at the sources of problems leading to burnout and so could aid in the development of more efficient prevention strategies. This model remains open for research to examine the worksite, the individual and the interaction between the two (Maslach \& Goldberg, 1998). The Conceptual Model was based on Maslach's multidimensional model focusing specifically on the worksite, leaving out any other potential variables that may cause burnout. 
Mediation model. Authors of a mediation model (Leiter \& Maslach, 2005) proposed to define burnout as the incongruence between six areas of working and the worker. The six areas include workload, control, reward, community, fairness, and values (Leiter \& Maslach, 2005). For this model, researchers developed a check-list survey to measure institutional well-being. Employees of a large university and hospital were asked to participate in this study. The goal was to test the validity of the mediation model within the two different settings. In the university setting, 905 surveys were distributed, and 740 were completed. Of 3,500 surveys distributed to employees of the hospital, 2,633 were completed and returned. The researchers used three measures to assess six areas of work life. These measures included the Maslach Burnout Inventory-General Survey (MBI-GS), the Areas of Work life Scale (AWS), and a series of items that measured evaluation of change. The mediation model was tested against the data received from the two samples using a structural equation-modeling program. This analysis was used to determine the overall fit of the model, and whether there were statistically significant findings for each of the six areas. The findings provided support for the mediation model, which showed evidence that burnout is related to individual commitment and is predictive of job-related outcomes, such as negative work behaviors. It is noted through the analysis that the complex relationship of these six factors with burnout was replicated in the two different organizations being studied. This finding has opened the way for additional research into the development of preventive measures. It is also important to note that the interpretation of these results should include an acknowledgement that they are based on selfreport data. This model is also based on the multidimensional model developed by Christina Maslach. Despite a thorough literature review, the Leiter and Maslach (2005) study is the only research I found on the mediation model. 
Developmental model. All research on burnout to date has included some discussion of how it develops over time (Maslach, et al., 2001). However, research on the development of this phenomenon has also been limited due to a lack of longitudinal studies. When describing a developmental model, Maslach, et al. (2001) stated that burnout occurs over time when exposed to chronic job stressors or because dedicated people do more than is professionally expected in order to support their own ideals. One of the most well-known developmental models is the phase model. The phase model uses the three dimensions described in Maslach's multidimensional model (Maslach, et.al, 1996). In this model it is postulated that burnout begins with depersonalization, followed by a decrease in personal accomplishment, then emotional exhaustion (Golembiewski \& Munzenrider, 1988; Leiter, 1993; Maslach, et.al, 2001).

An author of another developmental model, the process model (Leiter, 1993), proposed that work overload and interpersonal conflict were key components in the development of emotional exhaustion. Emotional exhaustion further promotes depersonalization, while the presence of social support and resources influences personal accomplishment. This model predicts that depersonalization and decreased personal accomplishment occur simultaneously. Again, developmental models of burnout have limitations due to the lack of longitudinal studies.

Social-exchange model. The social-exchange model proposed by Schaufeli, van Dietendonch and van Gorp (1996) includes social exchange at both an interpersonal and organizational level, and indicates a relationship between burnout and organizational commitment. The interpersonal level is the relationship between the caregiver, or therapist, and the recipient, or client. The organizational level refers to the interaction between the employee 
and the employing organization. Schaufeli, et al. (1996) tested the hypothesis that burnout is associated with reciprocity between patients and organization. They believe that organizational commitment is associated with reciprocity at the patient level. These hypotheses were tested using a linear structural modeling approach. Two samples were used, consisting of one sample of 1,220 student nurses, and another sample of 2,142 student nurses. Lack of reciprocity at a patient level was measured by asking the nurses how much appreciation was shown to patients, and by the level of investment in the nurse client relationship. Lack of reciprocity at the patient level was measured by items relating to the nursing relationship in both the work and training environment. Burnout was measured by using the Dutch version of the Maslach Burnout Inventory. Poor organizational commitment was measured by items from the Organizational Commitment Questionnaire. The study found that burnout is associated with social exchange relationships at the interpersonal level. Poor organizational commitment was found to have a positive correlation with lack of reciprocity at the organizational level, but not at the interpersonal level. These findings suggest, therefore, that a combination of individual and workplace interventions could be the most effective tools in reducing burnout. In each sample different scales were used to assess organizational commitment, and this caused internal validity problems. Cronbach's alpha was particularly low in the depersonalization scale within the nursing samples. The authors speculated that this is due to a personal enthusiasm, engagement and empathic concern at this time in their careers.

Conservation of resources model. The conservation of resources (COR) model proposed that burnout happens when a worker perceives a threat to his/her resources, loss of resources, or lack of expected return from time investment (Halbesleben, \& Bucley, 2004; Hobfoll, \& Freedy, 1993). Resources can be defined as objects, conditions, personal 
characteristics, and energies (Hobfoll, \& Freedy, 1993). Objects are items such as books, computers, and similar tools. Conditions may include environmental work conditions as well as quality of marriage. Therapy skills, patience, and stamina are examples of the personal characteristics referred to in this model. Energies are considered to be money, knowledge and endurance (Hobfoll, \& Freedy, 1993). When resources are threatened or taken away, psychological stress occurs. The key to this theory is the relationship between job demands, challenge to resources (in the form of psychological stress), and the development of burnout. This theory was based solely on a review of literature, and has no empirical research to back its findings.

Multidimensional model. Maslach (1982) explained burnout within a multidimensional framework. These dimensions include emotional exhaustion, depersonalization, and reduced personal accomplishment (e.g. Kahill, 1988; Maslach, 1986; \& Maslach \& Goldberg; 1998). Emotional exhaustion (EE) refers to "feelings of being emotionally overextended and exhausted by one's work" (Maslach, Jackson, \& Leiter, 1996, p. 4). Depersonalization (Dp) refers to “an unfeeling and impersonal response toward recipients of one's service, care, treatment, or instruction" (Maslach, et al., 1996, p. 4). Personal accomplishment (PA) refers to "feelings of competence and successful achievement in one's work with people" (Maslach, et al., 1996, p. 4). Thus, the concept is defined as a continuous variable, ranging from low to high degrees of the experience of burnout. A low level of experience of burnout would include low levels of EE and Dp, and high levels of PA, while a high level of experience of burnout would include high levels of EE and Dp, and low levels of PA. In this multidimensional model, all three components are required to label this phenomenon as burnout. For example, if an individual shows signs of EE, yet has high levels of PA, he/she is identified as being at high risk of 
burning out, not as being burned out. These levels can be measured using the Maslach Burnout Inventory (MBI). The MBI, a 22 item self-report inventory, and has been shown to be highly reliable with good attention to validation criteria for the three identified subscales. Convergent and discriminant validity was adequately described in this study (Arthur, 1990). It is because of the research done using the MBI that other models were developed based on the multidimensional model. Therefore, the multidimensional model and the MBI will be used exclusively for this study.

Research on burnout variables has shown a strong correlation to EE, but not Dp and PA (Maslach, 1993). This finding has led to suggestions that burnout is a unidimensional construct and that other factors should be dropped from the definition (Maslach, 1993; Shirom, 1989), yet unidimensional models have not been supported by empirical research. Burnout research has primarily been conducted on samples working in professions that demand a continuous high level of interaction, such as therapists, police officers, nurses, and social workers (Maslach \& Goldberg, 1998; Maslach, et al., 2001; Pines, 2005b). Even though this model was derived mainly from the above professions, it does not preclude the possibility that burnout can occur in other careers, although much more research is needed.

Experience of burnout. As previously noted burnout has been defined as the challenging (Hallsteen, 1993) or taxing of energy, resources and personal strength (Freudenberger, 1974). It has been attributed to the unceasing pressures of work with emotionally needy and demanding individuals, and employee response can include feelings of failure and exhaustion (Freudenberger, 1974). Researchers have further attempted to identify symptoms of burnout, and categorize them to include physical, emotional, psychological, and 
behavioral symptoms (Kahill, 1988; Maslach \& Gomes, 2006), with over 130 possible different symptoms having been identified (Burish, 1993).

Physical and cognitive symptoms. Physical symptoms include sleep difficulties, fatigue, headaches, and gastro-intestinal problems (Belcastro, Gold, \& Grant, 1982; Cherniss, 1980; Edelwich, 1980; Kahill, 1988; Maslach \& Goldberg, 1998; Miller, Stiff, \& Ellis, 1988; Wicks, 2008). Other physical signs may include dilated pupils, increased heart rate, and loss of energy that could lead to exhaustion (Kesler, 1990). With the loss of energy, time management skills are challenged (Belcastro, et al., 1982; Kesler, 1990). Cognitively, a counselor can develop perfectionism, disorganized thinking, and potentially even suicidal ideation (Kesler, 1990).

Psychological/emotional symptoms. Emotional symptoms can include depression, anxiety, boredom, anger, frustration, feeling unappreciated, nervousness (Burisch, 1993; Grosch \& Olsen, 1994; Hallsten, 1993; Kahill, 1988; Wicks, 2008), resentment, hopelessness, loss of charisma, feelings of futility, feeling fed up (Freudenberger, 1975; Kesler, 1990), and disenchantment (Freudenberger, 1975). A person who is truly burned out may find it difficult to hide these feelings (Freudenberger, 1975). Suspiciousness and irritation are also noted (Freudenberger, 1975). Burned out counselors can also feel incompetent, victimized, and helpless (Kesler, 1990). Attitudinal expressions may include cynicism, callousness, pessimism, defensiveness, intolerance, and a decrease in enjoyment (Kahill, 1988; Maslach, 1998; Thorpe, 2001). Burn out has also been shown to lower self-esteem (Kesler, 1990).

Recently, researchers have begun to examine the relationship between vicarious trauma, compassion fatigue, and burnout (Sprang, et al., 2007; Thorpe, Righthand, \& Kubik, 2001). Both vicarious trauma and compassion fatigue are terms used to describe secondary stress from 
working with distressed clients, including victims and/or perpetrators of sexual abuse.

Vicarious trauma results from repeated exposure to the trauma of others, which may lead to both cognitive and psychological effects in the therapist. Compassion fatigue is also associated with a progression from the psychological effects of vicarious trauma. One researcher asked 5,752 licensed or certified behavioral health providers to complete a 102-item survey soliciting information about provider practice methods, use of evidenced-based practices, knowledge of event-specific responses in different populations, barriers to effective treatment, and levels of compassion fatigue, compassion satisfaction, and burnout (Sprang, et al., 2007). The surveys were returned by 1,120 study participants. When specifically addressing a scale developed to measure quality of life from a section of the larger, 102-item survey, the researchers completed ANOVAs that showed a difference in compassion fatigue, and burnout as related to gender. Specifically, females had higher scores on these variables than males, meaning that females are more likely to experience compassion fatigue or burnout. It was also found through these analyses that there was a difference in compassion fatigue and burnout among different work environments (community mental health, public agency, inpatient facility, etc.). Overall, it was found that specialized trauma training reduced levels of compassion fatigue and burnout, and increased peer support, especially for those working in more isolated settings. To identify compassion fatigue, compassion satisfaction and burnout the researchers used the Professional Quality of Life Scale (ProQOL). The internal consistency of the ProQOL is adequate as indicated by Crombach's alpha ranges from .72 (burnout), .80 (Compassion Fatigue) to .87 (Compassion Satisfaction). The authors indicate the construct validity is good, yet do not describe these findings. The ProQOL scale is a 30-item self-report measure, which could lead to participants answering questions in a socially desirable manner. This would depend on what 
the researchers told the participants about the nature of the study. If the participants knew the study was about compassion fatigue or burnout, it is more likely that mental health professionals would attempt to make themselves appear better than they truly are. These socially desirable responses may be due to a lack of understanding of the questions as well as perceived societal taboos regarding burnout (Sprang, et al., 2007). This study was limited to licensed and certified professionals; paraprofessionals were not solicited to complete this survey. The response rate for this survey was $19.5 \%$. The researchers noted that there could have been valuable information from the non-respondents that cannot be accounted for in this study. The participants solicited were limited to rural southern states. There were limited follow-up reminders due to budget restraints. Although the number of responses received does appear to be an adequate sample size, limiting the sample geographically and by professional experience can reduce the ability to generalize the results.

In a study of private or state-owned companies in southern Poland, 80 managers, aged 27-46, completed questionnaires measuring burnout (MBI: Maslach Burnout Inventory), fluency, flexibility, originality of thinking (CAT: Consequences Anticipation Test and TDT: Test of Divergence Thinking), and level of innovation (Noworol, Zarczynski, Fafrowicz, \& Marek, 1993). Innovation is described as the discovery of a new or unusual idea through logic, experience, or artistry. Creativity refers to an original concept that is satisfying to the creator, meets a human need, and is innovative. The scores of the MBI were split into three clusters; cluster I having the lowest scores, indicating low or no burnout, cluster III having the highest scores on the MBI, thus indicating burnout. These cutoff points are not the standardized cutoff points as identified by the BMI; they were set by the researchers. These researchers did not identify what criteria were used to determine the levels of burnout, or which scores were used 
as cutoff points to identify the different clusters of managerial burnout. Therefore, this study could not be replicated to determine its reliability and validity. However, the study found a great difference in creativity in the comparison between those identified as burned out and those not showing signs of burnout. When examining fluency of thinking, the CAT and TDT indicated those in clusters II and III of the MBI scores met the criteria for blocked fluency of thinking. Flexibility of thinking and originality of thinking showed varied results in clusters II and III, while showing a significant difference in relation to cluster I. An examination of innovation revealed that cluster I placed at the innovative end of the continuum, while cluster II was spread out over the continuum, moving more towards adaptation and away from innovation. Other studies in addition to this one demonstrate that managers experiencing burnout show a reduction in creativity and innovation (Noworol, et. al. 1993). The small sample size $(\mathrm{n}=80)$ was limited to male managers, which limits the generalizability of the researchers' findings to other professions.

Innovation, creativity and flexibility of thinking are all important skills for therapists in work with clients. It is imperative for therapists to be flexible in their thinking, as well as creative and innovative in practice, since any client presenting for therapy will exhibit different presenting problems and react differently to the therapy relationship. Without flexible thinking, creativity, and innovation, a therapist may not be able to meet client needs, which is in itself a recognized form of impairment (APA, 2010).

In addition to being a psychological strain on the therapist, burnout negatively impacts the successful delivery of mental health services (Farber \& Heigetz, 1982; Masters, 2004). Farrenkopf (1992) addressed this issue, specifically looking at therapists who work with sex offenders through pilot interviews of 17 prison therapists, and then a structured questionnaire 
administered to 35 Oregon mental health therapists working with criminal clients and sex offenders. The results of this pilot interview indicated that $54 \%$ of the surveyed therapists negatively changed their outlooks on treatment and their expectations of the clients over time, although a specific time frame was not identified. Also $42 \%$ of the respondents showed an increase in hardened emotions with an inability to deal effectively with the behaviors of others. Of the respondents, $25 \%$ reported feeling burned out. The therapists became more pessimistic regarding client ability to change as well as focusing more on the "dark side of humanity" (Farrenkopf, 1992; Masters, 2004). The questionnaire included topics such as personal impact of working with this population, gender differences of therapists, coping strategies, and demographics of the participants. The results of the questionnaire indicated that females have an increase in vulnerability and threat of abuse. Farrenkopf (1992) identified four impact phases related to working with sex offenders. Phase One was "Shock”, identifying overwhelming feelings of the prevalence of abuse in society. Phase Two, "Mission", was the adaptation to the work, when a therapist is willing to work with clients concerned about effective treatment. Phase Three, "Anger", is the response to client denial and re-offense that is disheartening to the therapist. Phase Four, "Erosion", an extension of Phase Three, is defined as when anger turns to resentment. With coping strategies, therapists can move to Phase Four B, "Adaptation", or tolerance of the "human dark side". The coping strategies identified in this survey include diversifying work areas, increasing support systems, such as supervision, and attitude adjustment. Small sample size and sample pool was a limitation to this study. The pilot interview was completed with prison therapists, and the survey was given to mental health therapists. This limits the ability to correlate the information as the populations are so different and results are not generalizable to each population. 
Behavioral symptoms. Behavioral symptoms include poor performance on job related tasks, tardiness, and consumption of caffeine, alcohol, and drugs (Burisch, 1993; Grosch \& Olsen, 1994; Kahill, 1988; Kesler, 1990). Interpersonal symptoms include withdrawal from clients (Burisch, 1993; Masters, 2004), friends, and family (Jayaratne, Chess, \& Kunkel, 1986; Kesler, 1990), lack of pleasure in other aspects of life, and a loss of interest in professional resources (Kahill, 1988; Maslach 1998; Thorpe, 2001; Wicks, 2008).

In their review of the research, job performance and health were identified as the most studied outcomes (Maslach, et al., 2001). Burnout affects job performance by absenteeism, turnover, reduction in productivity, and an increase in conflict among co-workers (Grosch \& Olsen, 1994; Maslach, et al., 2001). Since employee health is affected in some of the same ways as exposure to prolonged stress (Kahill, 1988; Westman \& Etzion, 2001, Maslach, et al., 2001), a healthy, burnout free workforce may be both more productive and more cost effective (Maslach, 2001).

The list provided here is by no means exhaustive, and possibly may never be. Not all of these symptoms need to be present for someone to be burned out (Cherniss, 1980). Much more research is needed to develop an empirically based list of symptoms to develop a comprehensive definition. Maslach's multidimensional definition of burnout: “A psychological syndrome of emotional exhaustion, depersonalization, and reduced personal accomplishment that can occur among individuals who work with other people in some capacity" will be used in the proposed research study (Maslach, 1993, p.20). This model meets the needs of this study, as it has been developed through research with those who work with other people, is the predominant theoretical framework in this field (Maslach, et al., 2001), and 
has shown evidence of discriminant and convergent validity that will be discussed in greater detail in Chapter 2.

Ethical Considerations. Early identification of burnout is important to maintain professionalism and an ethical practice. The sooner a professional identifies symptoms of burnout, the less potential harm may be done to the client and the therapeutic relationship. Professional organizations, such as the American Psychological Association (APA) and the Association for the Treatment of Sexual Abusers (ATSA), have codes of ethics encouraging therapists to insure no harm is done to the populations they serve. The Ethical Principals of Psychology and Code of Conduct, Principal A: Beneficence and Non-maleficence (American Psychologist Association, 2010) states "Psychologists strive to benefit those with whom they work and take care to do no harm.... Psychologists strive to be aware of the possible effect of their own physical and mental health on their ability to help those with whom they work." (p. $3)$.

Psychologists need to be aware of burnout symptoms and to identify them as soon as they present. Acknowledgement of these symptoms allows professionals to take action before any harm is done to clients, communities, or to the therapist. While working with difficult clients and with prolonged exposure to traumatic events experienced and reported by clients, it is not uncommon for a professional to experience emotional distress. This emotional distress and burnout could potentially lead to impaired practice (Barnett, et al., 2007). As previously stated, impaired practice can lead to harm of clients, communities, and even therapists themselves.

The Professional Code of Ethics from the Association for the Treatment of Sexual Abusers (ATSA, 2001) reminds clinicians that "Members will not allow personal feelings 
related to a client's crimes or behaviors to interfere with professional judgment and objectivity." (p.3 Code 2(a)). When working with sex offenders, it is likely that therapists will hear stories that will evoke strong emotional responses, and challenge personal belief systems (Thorpe, 2001). Maintaining a high ethical standard means having personal beliefs and morals challenged, while still being able to act on behalf of the client. Furthermore, researchers (Zapf, et al., 2001) have identified a link that places therapists who work with sex offenders and hear such emotionally charged stories at high risk for increased emotional exhaustion and depersonalization, and therefore also at higher risk for burnout (Scoria \& Arrest, 1993). As mentioned previously, when a therapist suffers from burnout it negatively impacts treatment services (Farber \& Heigetz, 1982).

\section{Therapists Working With Sex Offenders}

It has been found that all the difficulties of clinical work, such as maintaining a therapeutic role, the non-linear nature of therapy, type of client, and work conditions (e.g. excessive case load) can create additional stressors for the therapist. While these stressors are inherent in the work of therapists in the helping profession, burnout can occur with the addition of other issues, such as strongly resistant clients, potentially suicidal individuals, and individuals suffering from personality disorders (Farber \& Heigetz, 1982).

Factors influencing burnout in therapists. In the attempt to develop a framework for the definition and treatment of burnout, theorists have identified key contributing factors. Hallsten (1993) identified three factors and Maslach, Schaufeli, and Leiter (2001) identified five common elements that precipitate burnout. Hallsten theorized that vulnerability, goal orientation, and an incongruous, threatening environment are constructs that promote burnout (1993). Vulnerability is seen as the condition of a person who has had troubling experiences 
that have created negative self-esteem issues. Goal orientation refers to individual long-term goals, occupational responsibility, and professional training. An incongruous, threatening environment is one that lacks social support and resources to meet organizational goals. A person with some history of troubling experiences, who is not goal oriented, and who lacks either competency or support may be more susceptible to burnout (Hallsten, 1993).

The five factors identified by Maslach et. al., (2001) are as follows: (1) dysphoric symptoms, such as depression, anxiety, and fatigue; (2) mental and behavioral symptoms such as cynicism, work tardiness, and an overall decrease in work performance; (3) these symptoms are work related; (4) all elements are found in a person who is not presenting with any other history of psychopathology; and (5) therapists more susceptible to burnout are those individuals perceived as vulnerable and lacking in goal orientation. Goal orientation is referred to as active participation in making changes within an organization that contributes to self-preservation. As with the five elements of burnout of Maslach, et al. (2001), Hallsten's (1993) three key contributing factors are supported throughout burnout research. Within these factors that precipitate burnout, there are personal and demographic characteristics that have been identified as predictors throughout other historical research into this phenomenon.

Gender. Historically, research on gender as a predictor of burnout has shown mixed results in research (Maslach \& Leiter, 2008). Some research has found no gender difference in burnout (Ackerly, et al., 1998; Pines, 1997; Shelby, et al., 2001), although others differ. One other study indicated that men are more likely to experience burnout (Maslach \& Jackson, 1984), while others have shown women to be more susceptible than men (Acker, 2003; Shirom, 1989; Sprang, et al., 2007). It has been postulated that women are more adept at using coping 
strategies to reduce burnout than men (e.g. Kramen-Kahn \& Hansen, 1998), but may exhibit more physical symptoms when the condition does develop (Shirom, 1989).

There are many potential reasons for such results. Every study used different samples, burnout models (unidimensional and multi-dimensional), and instruments (BMI, BI, or a quality of life survey). For example, in one study 259 mental health service providers, social workers and case managers working in outpatient settings, were asked to complete several self-report measures (Acker, 2003). The concepts measured included burnout, role conflict and role ambiguity, social support, and demographic variables. The demographic variables identified were time spent working with serious mental illness, worker age, gender, marital status, job experience, educational level, caseload size, and salary satisfaction.

Role conflict occurs when a worker has incompatible work requirements or different expectations placed upon him/her when working for different groups that may operate differently. Role conflict can also occur in workers who are not able to work autonomously with clients or are expected to work on tasks that may be unnecessary. Role ambiguity happens when workers are uncertain about how to perform their jobs or how their job impacts the clients they serve. The researchers used a Pearson product-moment correlation coefficient to determine if role conflict and ambiguity are related to increased levels of burnout. Three hierarchical regression analyses were completed, once for emotional exhaustion, a second for depersonalization, and the third for decrease in personal accomplishment to explore how role conflict and role ambiguity relate to demographic variables. It was found that females scored lower on the depersonalization scale (Acker, 2003), although earlier research had shown an increase in female emotional exhaustion (Maslach, 1982). The limitations of this study included using a convenience (those in close proximity of the researchers) sample of mental health 
providers, the use of self-report measures that could have resulted in socially appropriate responses, and lack of information from non-respondents. The results of other variables from the Acker (2003) study will be identified in the relevant sections.

In the past, researchers (Etzion \& Pines, 1986) have also examined the role of gender and culture in burnout. Five hundred and three social workers, teachers, managers and counselors were asked to complete the Burnout Measure and a work and life satisfaction questionnaire. Of these, 284 were Israelis and 219 were Americans; 216 were men and 287 were women. Using a two-way analysis of variance it was found that women reported significantly higher levels of burnout than men $(\mathrm{F}=25.29 ; p<.001)$. The researchers further explored how individuals cope with burnout, finding that cross-cultural differences are more significant than cross-gender differences. There is indication that in the Israeli culture, there is more support through social and supervisory means than in American culture. This difference in support of the professional is more significant than gender differences. The study of burnout across cultures is an area of research that requires further attention (Pines, 1997). It is also important to further studies across cultures. Those working in the helping professions are from many different cultures and to prevent and treat burnout in any culture it is necessary to learn more about how it affects practitioners from cultures.

When examining gender differences in therapists treating sex offenders, authors in the professional literature have identified that females are more prone to feelings of vulnerability and safety concerns (Leicht, 2008; Tyagi, 2006), generally responding more negatively to male sex offenders (Clarke \& Rogers, 2007), and experiencing more paranoia (Farrenkopf, 1992), any of which can lead to burnout over time (Leiter, Frizzell, Harvie, \& Churchill, 2001). Furthermore, females have reported a higher level of countertransference in work with incest 
abusers (Friedrich \& Leiper, 2006). This countertransference can result in more negative therapist reactions to clients and has thus been known to contribute to the development of burnout (Grosch \& Olsen, 1994; Leicht, 2008). It should also be noted, however, that work with sex offenders does not only negatively affect female therapists. Male therapists have also identified concerns of gender shame and a sense of "collective guilt" (Farrenkopf, 1992; Leicht, 2008). Collective guilt is the shame and guilt experienced through gender identity with those participating in malicious acts. They have also shown higher levels of cynicism, a detached concern or emotional distance that serves as protection from the intense emotional arousal that could potentially negatively impact work performance (Maslach et al., 2001).

The different results reported above are reflective of gender-role socialization (Sprang et al., 1998; Acker, 2003). Another potential reason for the difference is that women identify themselves as having more support outside the work environment (Sprang et. al, 1998). A person's willingness to disclose symptomology of burnout may also play a role in the different results among gender, since there are some who report that women are more willing to report symptoms (Sprang et. al, 1998).

Experience. Age and amount of time spent as a therapist have also been hypothesized to be factors increasing risk for burnout. The fewer the number of years in practice has been correlated with higher levels of emotional exhaustion and depersonalization, thus leading to higher levels of burnout (Maslach et al., 1996). In a study of 562 licensed, doctoral-level psychologists employed within human service settings, years of service were negatively correlated with emotional exhaustion and depersonalization scales on the MBI (Ackerly et al, 1998). Early studies have concluded that therapists in their first two to three years of practice (Shirom, 1989), were more likely to experience burnout. This was also true of those who work 
with sex offenders (Friedrich \& Leiper, 2006). However, this does not mean those who have been in the helping profession for longer periods of time are exempt from developing the same phenomenon (Linley \& Joseph, 2007).

To determine if early career burnout played a role in later career adaptation, Cherniss (1992) used the MBI and interviewed 25 human service professionals working in public law, nursing, teaching and mental health. The subjects were studied in their first year in the field and again approximately12 years later. The interviews explored dimensions of occupational satisfaction, internal work motivation, feelings about clients, trust of clients, and emotional detachment. Using correlational analyses and $t$-tests it was determined that there was no significant relationship between measures of work satisfaction or attitudes towards their clients over the 12 year period. Those who made a career change during the 10 years $(n=10)$ after the original study showed significantly less burnout at follow-up. Those who did not make a career change were described by informants as having an increase in flexibility $(r=0.50)$ and an openness to change at the follow-up survey. As previously noted, other research has shown less flexibility in burnout sufferers, so it must be noted that this result was unexpected. This longitudinal study began with interviews conducted by the researcher and graduate students. The subjects were interviewed at least twice. The follow-up interviews were conducted by the researcher only, and it was found impractical to complete multiple interviews. Also in the initial study, subjects completed interviews only. At the follow-up the subject and a confidante completed surveys. These inconsistencies limit the researcher in making true comparisons for all of the dimensions obtained in the surveys. Also, with a small number of subjects, the researcher was unable to complete multiple statistical analyses in order to determine a relationship with early career burnout and career adaptation variables. 
However, a clear correlation appears between age and onset of burnout among therapists (Maslach, 1982). Studies have shown that burnout is more likely to occur in younger therapists (Gerstein, Topp, \& Correll, 1987; Maslach \& Leiter, 2008) than those between 30-40 years old (Devilly et al., 2009; Maslach et al., 2001). Specifically, younger therapists experience more emotional exhaustion (Hyphatis \& Mavreas, 2005).

Level of training. It is through education and training that therapists learn new therapeutic techniques and skills (Cherniss, 1980). There has been concern that gaps in training could fail to prepare a new therapist for dealing with the interpersonal processes that occur throughout therapy interactions (Cherniss, 1993; West, 1996). It has also been noted that those whose training was limited to the undergraduate level were more likely to experience symptoms of burnout than graduate level therapists (Maslach, 1982; Maslach et al., 2001). Acker's study of 259 mental health service providers (2003) found that the higher the level of education the higher the scores on the emotional exhaustion and depersonalization scales of the MBI. It is noted that the difference in the results of the Maslach studies and the Acker study may be directly related to receiving less supervision and support from supervisors. In her book, Adrian West (1996) identified a connection between level of training (educational degree of therapist: doctoral, masters, or bachelors degree) and therapist self-awareness: the higher the level of training the higher the level of self-awareness. She concluded that this connection is true for all therapists, including those who are working with the offender population. Without sufficient training and supervision, personal reactions can easily lead to emotional exhaustion and higher levels of burnout (Cherniss, 1980), although others have found that training without supervisory support will have the same result (Acker, 2003). This difference is important to note, as the study being proposed will attempt to determine which variable has a greater impact on burnout. 
It is also necessary to note that personal feelings towards offenders cannot be ignored, as these feelings can change attitudes towards clients, and impede therapeutic efforts (West, 1996) despite education and training levels.

One aspect of education and training for therapists is their perceptions of the clients they treat. One area of research concerns clinician attitudes towards sex offenders. The Sanghara and Wilson (2006) study specifically investigated stereotypes and attitudes toward child abuse offenders. They surveyed experienced sex offender professionals, such as therapists, police officers, prison officers, etc., and professionals lacking such experience, such as school teachers. Sixty experienced and 71 inexperienced participants read six vignettes of suspected child abuse scenarios and then determined guilt or innocence based on the information presented. They were also asked to complete self-report questionnaires that measured attitudes towards sex offenders and knowledge of sexual abuse. The self-report measures had both positively and negatively worded questions. If the questions are not read carefully, the results could be invalid, as the answers could be marked inaccurately. The questions based on the child abuse scenarios were asking the participant to identify how guilty someone is on a 10point Likert scale (1=very unlikely, 10=very likely). There were no other anchor values given on the Likert scale; therefore the validity of the scale needed to be addressed. A preliminary confirmatory factor analysis of the vignette rating revealed five factors with minimum eigenvalue criteria ( $94 \%$ of the total variance). Both the consistent and inconsistent stereotypes were loaded on different factors, except for two stereotypes that were loaded on the same factor. Therefore, there are five-factor ratings for the six potential stereotypes. The results showed a difference between the two groups in stereotype endorsement with the inexperienced group having higher scores and less positive attitudes towards child abuse offenders, than the 
experienced group $t(129)=-8.64, p<.001$. The experienced participants showed a more positive attitude toward sex offenders and more accurate knowledge of child abuse than the inexperienced group.

Another way in which level of training affects a therapist's work with sex offenders is in the therapists' perceptions of the offenders. In a study investigating attitudes of professional counselors $(n=437)$ toward sex offenders (Nelson, Herlihy, \& Oescher, 2002), researchers used a self-report questionnaire adapted from the Attitude Towards Prisoners Scale (ATP). The word "prisoner" was replaced with the words "sex offender" to create the Attitude Towards Sex Offenders Scale (ATS). A higher score on the ATS indicates a positive attitude toward sex offenders and lower scores indicate more negative attitudes towards sex offenders. Cronbach's alpha was computed at .92 for this study. Previous studies indicate that the ATP has acceptable test-retest reliability, internal consistency and construct validity. The construct validity of the ATS was established by administering the measure to different groups and comparing the means. Although the ATS was adapted from the ATP, there is a lack of the strong validity and reliability testing of the ATS. A demographic questionnaire was also sent to participants asking for information about work experience with sex offenders and personal information such as age, gender, and educational level. It was found that overall counselors had a more positive attitude toward sex offenders, by showing higher than average scores on the ATS. After receiving training specific to work with sex offenders, scores on the attitude scales increased, showing more positive attitudes. The results of both studies have shown that negative attitudes decrease with experience and training. There are a few limitations to this study, including the use of selfreport measures and the concern for social desirability. Since counselors were the only professionals surveyed, the results cannot be generalized across service populations. 
Theoretical orientation. Practicing therapists use different theoretical orientations to shape their work. Of the numerous orientations available, therapists who work with sex offenders are more likely to use psychodynamic or cognitive behavioral therapies (Craig et al., 2003; Freidrich \& Leiper, 2006; Linley \& Joseph, 2007; Marshall \& Serran, 2004; Shelby, et al., 2001). In the Shelby et al. study, $70 \%$ of licensed mental health providers who responded identified the use of cognitive techniques as their principle intervention in work with sex offenders (2001). Lindley and Joseph (2007) explored the positive and negative aspects of therapist $(n=156)$ wellbeing through the completion of seven questionnaires that measured the experience of client work and effects of this work on the therapist. Their analysis found that therapists using cognitive behavioral therapy had higher rates of burnout and were less likely to report personal growth and positive change within themselves when compared to therapists using other theoretical orientations, such as client-centered, psychodynamic, existential, integrative, and eclectic techniques. One of the limitations in this study was the lack of an instrument that measures burnout, although the authors do report that participants reported burnout. Other researchers using the Maslach Burnout Inventory (MBI) to measure burnout have found that therapist theoretical orientation is not a significant predictor of burnout level in the therapists they studied (Ackerley, et al., 1988; Shelby, et al., 2001). The Lindley and Joseph (2007) study specifically asked therapists to complete surveys describing "therapist experiences", while other studies did not indicate what specific surveys participants were using. This could have influenced study completion, as those who are asked to complete a survey about burnout may be sensitized to the issues of burnout (Maslach, et al., 1996), and so may respond in a more socially acceptable manner. 
Treatment Modality. Treatment of sex offenders can be facilitated in groups or on an individual basis. In a study of factors that contribute to burnout among sex offender treatment providers, licensed mental health providers $(n=86)$ completed the MBI and a demographic form (Shelby, et al., 2001). Of the $86,55.8 \%$ worked in group therapy settings. Using a bivariate analysis between treatment modality, individual or group therapy, no difference was found in relationship to the level of burnout (Shelby et al., 2001). It does seem that treatment modality is also an area that requires further research as this study is the only one found which refers specifically to the sex offender population.

\section{Influence of Work Place Environment}

As previously noted, research on burnout began with a primary focus on occupational settings and the effect of work stress on productivity and outcomes. Common elements of occupational settings that were studied included supervision, type of work setting, and caseload/work load. Each of these elements will be discussed for this research specifically in terms of the helping profession.

Supervision. Supervision in human services agencies serves several important functions for the therapist (Cherniss, 1980; Dillenburger, 2004; Ennis \& Horne, 2003; Kadambi \& Truscott, 2006). These include providing professional information and instruction, feedback and evaluation for performance standards, and vital social support. It is during supervision that a therapist can discuss client issues, transference and countertransference dilemmas, as well as personal issues that may get in the way of providing services (Ennis \& Horne, 2003).

Supervision is seen as a key component in coping and succeeding in the human service field, especially when working with more challenging populations such as sex offenders (Dillenburger, 2004; Kadambi \& Truscott, 2006). It is even more necessary in the forensic 
setting to provide a venue to discuss the fear, anxiety, and personal responses to clients, which will in turn promote positive well-being and decrease burnout (West, 1996).

The amount of supervision and social support have been found to have a negative correlation with burnout (Cherniss, 1980; Clarke \& Roger, 2007; Elloy, Terpening, \& Kohls, 2001; Farrenkopf, 1992; Maslach, et al., 1997; Ross, et al., 1989), especially in the domain of personal accomplishment (Jayaratne, et al., 1986). Following initial interviews of 17 prison therapists, Farrenkopf (1992) presented a questionnaire to 35 Oregon mental health therapists working with sex offenders, as a pilot study. Twenty-four of the surveys were returned and completed. Thirty-eight percent of the respondents expressed lack of a support system. It was proposed to increase or develop a social support system through supervision, peer groups, and case staffing. Each of these support systems could play a role in decreasing the level of staff burnout (Frankenkopf, 1992; Sprang, et al., 2007), as well as compassion fatigue (Sprang, et al., 2007). In an investigation of the relationship between burnout, social support and job experiences in 169 doctoral level staff working in a college counseling center (Ross, et al., 1989), a multiple regression analysis of the data indicated that social support from supervisors and colleagues was associated with lower levels of burnout. These findings indicated that support measures explained $3.5 \%$ to $11.4 \%$ of the variance in burnout scores over the counselor, work setting characteristics and job related stress on burnout (Ross, et al., 1989). Higher levels of job stress correlated with higher levels of burnout (Ross et al., 1989; Zapf et al., 2001). Those who received direct feedback on job performance reported less burnout (Cherniss, 1980; Maslach, 1997). It should be noted that one of the limitations in each of these studies was the lack of identification of supervision type: individual or group, as well as the amount of time spent in supervision. Also, it is noted that the study participants all worked in a college 
counseling center, so the results cannot be generalized to others in the helping profession without more research.

Work setting. Therapists work in different settings such as outpatient/community, inpatient/residential and prison/correctional settings. Research has shown that each work setting includes its own stressors, and that burnout is environmentally based (Kesler, 1990). These stressors have played a role in the formation of symptoms that relate to burnout (Bowden, 1994). Specifically, it has been found that therapists working in institutional settings reported high levels of depersonalization while those working in community settings reported a greater sense of personal accomplishment (Clarke \& Roger, 2002; Gerstein, et al., 1987), related to regular contact with clients (Clarke \& Roger, 2007; Cherniss, 1980; Shirom, 1989) and perceived danger (Garland, 2002; Masters, 2004; West, 1996). Regular contact with clients is described as a client's ability to see the therapist daily such as in prison and residential settings, as opposed to an outpatient setting where therapists see clients typically one hour a week or less. Perceived danger is described as conflicts among staff, interactions with manipulative and resistant clients, and fear of clients in general (Shirom, 1989). In the past researchers have stated that it is not the amount of direct contact with clients, but the type of presenting problems that creates the most negative influence on the therapist (Cherniss, 1980). The presenting problem of clients such as abuse victims and sexual offenders may promote more symptoms of burnout in therapists when compared to the amount of time spent with clients in general (Leicht, 2008).

Three common settings for working with sex offenders are prisons, inpatient hospitals, and outpatient clinics. While working in any of these settings, a therapist may develop some underlying fears. Fear can be used as a defense against potential unpredictable circumstances, 
such as physical attacks from clients or hearing details of offending behavior (Clarke \& Roger, 2002; Shirom, 1989; West, 1996). Defensive reactions such as fear and anxiety may limit therapist emotional availability, which in turn can lead to a decline in the level of service provided to clients. Some therapists working in forensic settings have chosen to leave their jobs for their own personal and professional survival because of fear, anxiety, and personal responses to these difficult clients (Samenow, 2004; Strasburger, 2001). It is noted that research has not yet confronted the occupational hazards of treatment inside institutions such as prisons, and thus burnout may remain undetected in this work environment (Garland, 2004).

Job imbalance between administrative and clinical work, conflict, and low co-worker support, combine to create a job setting that insures emotional tension and unrealistic expectations (Elloy, et al., 2001; Grosch \& Olson, 1994; Leiter \& Maslach, 2005). This combination produces the exhaustion characteristic of burnout. An examination of influential organizational factors led researchers to propose the mediation model (Leiter \& Maslach, 2005) briefly described earlier. As noted, this model was developed primarily from a study of participants in university and hospital settings. Using structural equation modeling, a link was found between organizational context and work-related outcomes in professionals experiencing burnout. This research study showed that reward (reinforcements), community (social support) and fairness (social justice) are critical as predictors in these settings. There was also a greater potential for burnout when organizational workers have lower perceived levels of reward, community and fairness (Elloy, et al., 2001; Maslach \& Leiter, 2008). Social factors such as role conflict and time pressures, political factors such as organizational mergers, and economic factors such as work load and downsizing were variables that have also been found to be related 
to burnout (Maslach, et al., 2001). An increase in any of these factors has the potential for increasing in burnout (Kramen-Kahn \& Hansen, 1998).

In Shelby, et al.'s research (2001), 43\% of those who participated ( $\mathrm{n}=86)$ worked in inpatient facilities or prisons, $51 \%$ worked in outpatient facilities, and $6 \%$ worked in both types of facilities. A significant difference was found between work settings, with those working in inpatient and prison settings showing higher levels of emotional exhaustion and depersonalization. A lower level of personal accomplishment was also found in inpatient and prison settings when compared to outpatient settings. A regression analysis indicated that inpatient and prison settings were the only variables found to be significant predictors of burnout (Shelby et al., 2001).

Caseload. Helping professionals often have significant managerial and clerical tasks in addition to maintaining the required interaction with clients, and the management of all of these responsibilities can be difficult (Acker, 2003; Cherniss, 1980). Excessive workloads have been known to contribute to a perceived lack of success in the workplace, which positively correlated with burnout and decreased client satisfaction (Cherniss, 1980; Dillenburger, 2004; Ennis \& Horne, 2003; Farber, 1982; Garman, Corrigan, \& Morris, 2002; Koeske \& Koeske, 1989; Kramen-Kahn \& Hansen, 1998). In a nationwide survey (Maslach, et al., 1997), it was found that people who spent most of their work time in contact with the public as part of their professional duties and also had large caseloads scored high for Emotional Exhaustion and Depersonalization and low on Personal Accomplishment (which is scored opposite to Emotional Exhaustion and Depersonalization) on the MBI.

A longitudinal research study found evidence that role conflict, role overload, and role ambiguity at work were significant predictors of burnout over a one year period (Perio, 
Gonzalez-Roma, Tordera, \& Manas, 2001). The participants in this study included members of primary health care teams and mental health care teams. The 29 primary health care teams consisted of physicians, nurses, social workers and administrative personnel, while the four mental health care teams consisted of psychiatrists, psychologists, nurses, and administrative personnel. Role conflict was defined as incompatible demands from "role senders". Role ambiguity referred to lack of clarity in job expectations. Role overload referred to an excess of qualitative or quantitative work. These variables were measured through a self-report questionnaire and the MBI was used to measure burnout. The surveys were dropped off by one of the researchers and they were completed and returned by mail, therefore it is impossible to determine if the participants actually were the ones who completed the surveys. This study, as with others, uses self-report measures where social desirability could have a negative impact on the reliability of the study. Through cross-sectional correlations, researchers found that role conflict and role ambiguity positively correlated with emotional exhaustion and depersonalization in the first data recording. With respect to personal accomplishment, role ambiguity presents with a negative correlation. These patterns remained consistent at the time of follow-up. This supports the hypothesis of the researchers that role conflict, role ambiguity, and role overload are significantly correlated with two of the three dimensions of burnout, emotional exhaustion and depersonalization. Other researchers (Sprang, et al., 2005) found similar results in a study that examined the relationships among compassion fatigue, compassion satisfaction, and burnout. They found that variables similar to role conflict, role ambiguity, and role overload increased compassion fatigue and burnout, while decreasing compassion satisfaction. 
Self-efficacy, or the personal belief in the ability to perform job-related tasks, was found to be negatively associated with burnout (Cherniss 1993). Research indicated that professionals who do not feel successful in their jobs for various reasons including high work load and the inability to complete tasks due to time constraints, experience difficulty in maintaining high self-efficacy (Cherniss, 1993). It is difficult for most professionals in any career to accept that they are unable to successfully complete the job they are required to do; therefore, the challenge of maintaining self-efficacy encourages burnout (Cherniss, 1993). This was supported by a study looking at four different professionals; a nurse, a teacher, a manager, and an entrepreneur (Pines, 2005b). Each individual presented for therapy due to problems related to burnout. Each person participated in 12-24, 50-minute sessions of psychoanalytic existential clinical work that focused on their childhood, family dynamics, occupational choice, professional goals and the relationship between childhood, occupational goals, and burnout. This study found that the primary cause of burnout appeared to be related to the goals and expectations that participants had upon entering their fields, as well as their perceived failure in attaining these goals.

\section{Factors Specific to Working with Sex Offenders}

Treatment of sex offenders is a slow, long-term process that is identified as one of the most stressful activities within any helping profession (Lowe, 2001). Sex offenders participate in illegal activities that are emotionally and sexually stimulating to them. These behaviors are kept secret from others as a necessary means to continue the activities. When they are asked or confronted about these behaviors, they may become defensive and will likely deny, minimize or rationalize their behaviors (Clarke \& Roger, 2002). As a result, it is important that a therapist working with sex offenders not be in any way psychologically impaired (Shelby et al., 2001). 
Not only would impaired clinicians provide substandard treatment and represent a waste of limited resources, society also relies on therapists to help rehabilitate sexual offenders to preclude further harm to others and to break the cycle of further victimization (Thorpe, 2001).

Therapist coping skills may be challenged when working with sex offenders, as therapists hear client fantasies and feelings, and the details of sex crimes that may have unexpected effects on the therapist (Farrenkopf, 1992; West, 1996). Blanchard (1998) wrote,

Our own happiness rests in part with our willingness to grow in the ways these troubled men are subtly guiding us. To hear of their pain and to be a part of their change process can enrich the life of the therapist. We must be willing to recognize our collective humanity and attempt to connect with all people if we are to create a safer society. (pp. 67-68)

This quote describes the power of this work and the struggle that therapists face while also eloquently describing the potential danger that can entrap therapists. These jobs are difficult and thus by definition may promote burnout. It becomes a vicious cycle because when therapists suffer from burnout, they become less effective at their jobs. Researchers have also found that both individuals who work with victims of sexual trauma and individuals working with offenders of trauma are prone to vicarious trauma and compassion fatigue (Barnett et al., 2007; Thorpe et.al. 2001).

In the book, The Difficult Connection (Blanchard, 1998), there is a focus on the therapeutic relationship as a means to insure productive treatment with clients such as sexual offenders. It is noted that when the therapeutic relationship is lacking there appears to be little movement in therapy. To build this relationship with a sex offender is stressful, as sex offenders usually present as unmotivated, deceptive, and manipulative (Masters, 2004; 
Samenow, 2004; Shelby et al., 2001). This therapeutic condition frequently leads therapists to believe that there is little hope for improvement (Blanchard, 1998). This belief in turn frustrates a therapist and symptoms of burnout may result (Kahill, 1988). While acknowledging that clinical work will be stressful at times (Farber \& Heigetz, 1982), therapists expect their work to "pay off" and to help the people they treat (Kadambi \& Truscott, 2006). By extension, this successful treatment will positively impact society. In a study of 82 Canadian professionals who work with sex offenders, it was found that a primary motivation to continue the work resulted from the positive impact of their work on the community, with a resulting increase in the Personal Accomplishment scale of the MBI (Kadambi \& Truscott, 2006; Leicht, 2008).

In order to improve treatment effectiveness for professionals working with sexual offenders, it is important to identify those primary factors that contribute to high burnout levels (Shelby et al., 2001). This is vitally important since the recidivism rate for sexual offenses is high (Craig et al., 2003). There are critics of the measurement of recidivism since it is usually measured by reconviction rates, not necessarily re-offending rates (Craig et al., 2001). This could be seen as a lack of treatment success, which is identified as one of the main difficulties in treating sex offenders (Friedrich \& Leiper, 2006). With such high recidivism rates, therapists will struggle with the question of whether the client is really being helped, which in turn may further promote burnout (Pines, 2004).

\section{Summary}

This study will identify the categorical variables influencing burnout specifically with therapists treating sexual offenders. There have been numerous studies over the past 40 years examining burnout and the consequences of that for both client/counselor therapeutic 
relationships as well as the negative impact on therapeutic effectiveness. Research that examined how this concept affects therapists treating sex offenders began in the 1990's. Many related variables have been identified including: gender, lack of or limited training, lack of or limited supervision, work environment, and the three dimensions of burnout (emotional exhaustion, depersonalization, and reduced personal accomplishment).

It is possible that the projected research findings will provide information that enables practitioners in this field to take precautions and make the necessary adaptive changes to prevent burnout. The prevention of burnout in therapists working with sex offenders is vital because communities rely on therapists to work with this challenging population in order to make their communities safer (Blanchard, 1998). Thus, the identification of the variables that increase burnout is necessary to make changes in order to maintain treatment effectiveness (Savivki \& Colley, 1982; Shelby et al., 2001). As reviewed previously, impairment is specifically identified in the ethical codes of both the APA and ATSA, and contains the proviso that a therapist is not to conduct therapy if impaired in any way. As the described literature indicates, impairment is one of the consequences of burnout. 


\section{Definition Of Terms}

Burnout: Negative response to prolonged emotional and interpersonal work stressors, to include the experience of individuals facing stressors (Maslach \& Goldberg, 1998)

Compassion fatigue: Negative response to difficult client information associated with a progression of psychological effects of vicarious trauma in the therapist (Sprang, et al., 2007).

Countertransference: Emotional reaction of a therapist in response to client statements (Strasburger, 2001).

Depersonalization (Dp): “An unfeeling and impersonal response toward recipients of one's service, care, treatment, or instruction" (Maslach, et al., 1996). Having no emotional response towards the sex offender or the stories they share.

Emotional exhaustion (EE): "Feelings of being emotionally overextended and exhausted by one's work." (Maslach, et al., 1996) This is when a therapist is emotionally drained, unable to handle any more emotional stress or stories.

Recidivism: Repeated relapse, or reoffending in a criminal manner (Craig, et al., 2009)

Reduced Personal Accomplishment (PA): “Lack of feelings of competence and successful achievement in one's work with people." (Maslach, et al., 1996) This is when a therapist feels as though they are no longer being successful in their jobs. 
Self-efficacy: Individual belief in the ability to perform job related tasks (Charness, 1993)

Vicarious trauma: Changes in the cognitive schema of a therapist who treats survivors of trauma (Leicht, 2008). These changes generally surround areas of safety, trust, and power. 


\section{Chapter II Method}

The purpose of this study was to explore the interaction of variables that create a state of burnout in therapists working primarily with a population of sexual offenders. The statistical analysis produced a dendrogram (classification tree) that displays the relative importance of statistically significant independent variables on the dependent variable. The dependent variables for this study are high or low degree of burnout, and average degree of burnout in therapists working with sexual abusers based on their results on the MBI. The independent variables are demographics (gender, current age), training (level of therapist training, years of experience working with sexual abusers, theoretical orientation of therapy used) and environmental work characteristics (amount of supervision, number of hours worked per week, percentage of sexual abuser clients, individual or group therapy, and work setting). The following sections describe the sample participants and the selection process used to recruit participants. In addition, the instruments used for this study, including reliability and validity, as well as the process of data collection, will be discussed.

\section{Participants}

Therapists currently working with sexual abusers in a therapeutic setting were recruited for the study. The participants were recruited from a list of providers who are members of the Association for the Treatment of Sexual Abusers (ATSA) and participants in the ATSA LISTSERV. Permission to use this membership list was obtained. The participants were approached by e-mail through the LISTSERV (Appendix A).

The number of participants suggested for the survey is 200 , determined by completing a power analysis to find an effect size of 0.1 , employing statistical power of 0.8 , with an alpha level of .05 (Field, 2005). Given that the typical average return rate of surface mailed surveys 
has been approximately 20-30\% (Patten, 2007) it was necessary to reach out to at least 1000 participants. One study that compared on-line surveys to mailed surveys found that a web survey could achieve a comparable response rate to a surface mail survey (Kaplowitz, Hadlock, \& Levine, 2004). In addition, the return rates of both e-mailed and surface mailed surveys can be influenced by follow up contacts since return rates show an increase with at least one follow up (Sheehan, 2001).

Participants were recruited from a list of providers who are members of the Association for the Treatment of Sexual Abusers (ATSA) as well as participants in the ATSA LISTSERV. There were approximately 1750 members of ATSA. There were 210 respondents over a threemonth period. Eight participants were excluded for failure to complete any questions on the MBI, 15 were excluded for working outside the United States, and 17 were excluded for having a caseload with less than $30 \%$ sexual offenders (one participant met two of these criteria). Twenty more were eliminated as they did not answer questions on the MBI that did not allow for scoring of one or more subscale; therefore a score for burnout was unattainable. Therefore, the sample used for this study is $n=151$ with a statistical power of 0.68 , a medium level of power.

\section{Design}

A retrospective comparative design was used for this research. The independent variables are demographics (gender, current age), training (level of training as a therapist, years of experience working with sexual abusers, theoretical orientation of therapy used) and work environment characteristics (level of supervision, number of hours worked per week, percentage of clients who are sexual abusers, individual or group therapy, and age of clients). 
The dependent categorical grouping variable is burnout status: high degree of burnout, average degree of burnout, or low degree of burnout as established through the results of the MBI.

It must be noted, however, that there may be some limitations to this use of a comparative design. If a relationship is found, it may result from extraneous factors. For example, if differences in burnout status are found in work environments, that may be a consequence of different personality characteristics of those therapists entering these types of work settings rather than the dimensions of burnout.

Thus, several precautions were taken to address the issue of internal and external validity in this research study. Surveys were sent to potential participants from different work settings nationwide in order to increase representation in the sample. Therapists working with sex offenders less than $30 \%$ of the time were excluded from the sample, which should increase the validity of the study by insuring that the sample is most closely representative of the desired population. Those working outside the United States were also excluded to maintain a nationwide sample.

\section{Measures}

The documents used to obtain data from each of the participants included a demographic and work characteristic questionnaire, and the Maslach Burnout Inventory. In 1990, Nancy Arthur examined three different assessments of burnout: the Maslach Burnout Inventory (MBI), the Staff Burnout Scale, and The Tedium Scale (later referred to as the Burnout Measure). In addition to a determination of the reliability and validity of each measure, each scale was described in detail and related research was outlined and reviewed. The MBI, which is a 22item self-report inventory, was shown to be highly reliable with good attention to validation criteria for the three identified subscales. Convergent and discriminant validity was adequately 
described in this study. Since the other two assessment tools lacked evidence for adequate testing of reliability or validity, the MBI was used exclusively for this study.

Demographic and work characteristic questionnaire. Demographic and work characteristic information was gathered via questionnaire. Participants were asked to identify: gender, age, level of training as a therapist (masters, doctorate), years of experience working with sexual abusers, theoretical orientation of therapy used, amount of supervision received on the job, size of caseload, percentage of sexual abusers on therapist caseload, individual or group therapy, and level of external stress (see Appendix B).

Maslach Burnout Inventory (MBI; Maslach, Jackson, \& Leiter, 1996). The MBI is used to address three general scales: (1) Emotional Exhaustion (EE) which measures feelings of being emotionally overextended and exhausted by the work; (2) Depersonalization (DP) which measures an unfeeling and impersonal response towards recipients of service, care treatment, or instruction; and (3) Personal Accomplishment (PA) which measures feelings of competence and successful achievement in the work (Gabassi, et al., 2002). To meet the definition of high degree of burnout, a participant exhibits high scores on EE $(\geq 27)$ and DP ( $\geq$ $13)$, and a low score on PA $(\leq 31)$. Average degree of burnout is defined by an average score on all three subscales, EE (17-26), DP (7-12) and PA (38-32). Low degree of burnout is defined by a low score on EE $(\leq 16)$, DP $(\leq 6)$, and a high score on PA $(\geq 39)$ (Maslach, et al., 1996).

The internal reliability coefficients for the three subscales of the MBI are: .90 for Emotional Exhaustion, .79 for depersonalization, and .71 for Personal Accomplishment with a standard error of measurement for each of 3.80, 3.16, and 3.73 respectively (Maslach, et al., 1996; Schaugeli, Enzmann, \& Girault, 1993). Convergent Validity has been demonstrated in 
three ways: (1) MBI scores are correlated with behavioral ratings from someone well acquainted with the participant therapist; (2) MBI Scores are then correlated with present job characteristics that contribute to burnout; and (3) MBI scores are further correlated with measures of different outcomes that have been hypothesized to be related to burnout (Maslach \& Jackson, 1981).

Discriminant validity was tested by asking graduate students to complete the MBI and the Crown-Marlowe Social Desirability Scale. This test indicates that burnout is not influenced by a social desirability response set. An empirical test for discriminant validity has shown that burnout is a three-factor syndrome in which each component is more closely tied to each other than to any component of depression (Maslach \& Jackson, 1981). Lee and Ashworth (1990) investigated Maslach's three dimensions of burnout, namely emotional exhaustion, depersonalization, and personal accomplishment, in supervisors and managers in the human service field. After a series of factor analyses, it was found that the three dimensions described by Maslach in 1982 were supported in this study by a high correlation to the variables reflecting aspects of strain, stress coping, and self-efficacy.

\section{Data Collection}

At least one thousand ATSA providers nationwide were solicited for participation in the study by e-mail. The invitation to participate included an informed consent notice, questionnaire requesting demographic and work characteristic information, and the MBI. The participants were then given a link to complete the surveys through Survey-Monkey. SurveyMonkey then compiled all the data so that individual respondent information would remain confidential. Each potential participant was asked to reply to this survey within two weeks of receipt. Reminder e-mails were sent bi-monthly for three months after initial posting. A total 
of 210 participants responded to the invitations. Of these, 59 were excluded for working outside of the United States and/or having less than $30 \%$ of sex offenders on their caseload. With the lower number of participants, the power of this study decreased from 0.8 (with 200 participants) to 0.68 (with 151 participants).

The testable hypothesis for this study identified only three independent variables as potential outcomes for the dependent variable of burnout. Given that this is an exploratory study, all variables described in the literature review will be used when performing the analyses, as it is important to remain open and flexible to unknown or unexpected outcomes of relationships between the independent variables and dependent variables.

\section{Data Analysis}

Descriptive statistics, such as means and standard deviations were computed for all demographic information and subscales from the MBI. These descriptive statistics were then used to describe the sample of responding therapists. The sub-groupings, high degree of burnout, average degree of burnout or low degree of burnout, were identified by scoring the MBI for each participant. Each participant received a score for each of the subscales of the MBI, to include Emotional Exhaustion (EE), Depersonalization (DP), and Personal Accomplishment (PA). The PA subscale is analyzed in reverse. To meet the criteria for high degree of burnout, a participant will have high scores on EE ( $\geq 28)$ and DP $(\geq 11)$, and a low score on PA $(\leq 29)$. Average degree of burnout is defined by an average score on all three subscales, EE (17-27), DP (6-10) and PA (36-30). Low degree of burnout is defined by a low score on EE $(\leq 16)$, DP $(\leq 5)$, and a high score on PA $(\geq 37)$ (Maslach, et al., 1996). 
Single sample $t$-tests were completed to compare the means of this sample to the means of the overall sample used to standardize the MBI Human Services Survey, and two of the Occupational Subgroups (Social Services and Mental Health subgroups). The single sample $t$ tests show that the means are significantly different for all three subscales when compared to the overall sample, EE and PA were different when compared to Social Services subgroup and DP and PA were different when compared to the Mental Health subgroup. The results are presented below and further implications will be revieweded in the discussion section.

The quantitative analysis was done using a Chi-squared Automatic Interaction Detector (CHAID) Technique analysis. While the CHAID technique has traditionally been used within business and marketing research, its use in rehabilitation and mental health studies has recently also been on the increase (Chan et al., 2005; O'Connell et al., 2006; Welte, Barnes, Wieczoreck, \& Tidwell, 2004).

CHAID is a non-parametric analysis based on statistically recursive partitioning algorithms (O'Connell et al., 2006). The CHAID Technique determines the relative importance of each of the independent (predictor) variables in explaining group membership in a categorical dependent (outcome) variable (Tabachnick \& Fidell, 2006). This technique employs two steps. In the first, the independent variables are stratified into alternative ordinal groupings to help insure similar percentage distributions of the dependent variable among the new categories. Groups may be formed from any possible combination of the levels of an independent variable, or by placing cut-points at any values of a continuous predictor. Second, this technique utilizes $\chi^{2}$ significance levels to determine which independent variable explains the most variance in the dependent variable. This process is repeated for all significant predictor variables until obtaining significant $\chi^{2}$ values is no longer possible. The CHAID 
analysis controls for Overall Type I Error by keeping the alpha level at .05 for each independent variable test run on a specific set of variable.

Dendrograms (i.e., classification trees) were utilized in this research to display the relative importance of statistically significant independent variables on the dependent variable. The hierarchical nature of the CHAID dendrograms provides a visual depiction of criteria and predictor variable interactions that may not otherwise be observable or detectible through traditional analytic procedures (Chan et al., 2005). The variable at the highest level of the tree is determined to have the closest statistical association with the dependent variable (O'Connell et al., 2006).

\section{Hypothesis}

Based upon the literature review, the hypothesized outcome of this study would be that work environment, specifically prison/correctional setting, would be the most influential variable in the development of burnout. Although there are many studies indicating the work environment is a variable in the production of burnout, this is the first study using the CHAID analysis to identify the most significant variable of burnout. Support for this hypothesis includes the reported high level of depersonalization found in those who work in institutional settings when compared to those who work in community settings (Clarke \& Roger, 2002;

Gerstein, et al., 1987) related to regular contact with clients (Clarke \& Roger, 2007; Cherniss, 1980; Shirom, 1989) and perceived danger of working in this setting (Garland, 2002; Masters, 2004; West, 1996). 
$\mathrm{H}_{0}$ : There is no statistically significant relationship between the incidence of prison/correctional setting and high levels of burnout.

$\mathrm{H}_{\mathrm{a}}$ : There is a statistically significant relationship between the incidence of prison/correctional setting and high levels of burnout.

The second most influential variable is hypothesized to be gender. In past research gender has mixed results throughout historical research (Acker, 2003; Ackerly, et al., 1998; Maslach \& Jackson, 1984; Maslach \& Leiter, 2008; Pines, 1997; Shelby, et al., 2001; Shirom, 1989; \& Sprang, et al., 2007). It is hypothesized that being a female would be more likely to be related to burnout when working with sex offenders than being a male (Leiter, Frizzell, Harvie, \& Churchill, 2001). Females are more prone to feelings of vulnerability and safety concerns (Leicht, 2008; Tyagi, 2006), generally respond more negatively to male sex offenders (Clarke \& Rogers, 2007), and experience more paranoia (Farrenkopf, 1992), as well as the reported higher levels of countertransference in work with incest abusers (Friedrich \& Leiper, 2006).

$\mathrm{H}_{0}$ : There is no statistically significant relationship between gender and high levels of burnout. $\mathrm{H}_{\mathrm{a}}$ : There is a statistically significant relationship between gender and high level of burnout.

The third variable that is hypothesized to be the most influential to burnout is supervision. It is hypothesized that the lower amount of supervision, the higher degree of burnout. Supervision is seen as a key component in coping and succeeding in the human service field, especially when working with more challenging populations such as sex offenders (Dillenburger, 2004; Kadambi \& Truscott, 2006). In past studies, it has been identified that the amount of supervision and social support has been negatively correlate to burnout (Cherniss, 1980; Clarke \& Roger, 2007; Elloy, Terpening, \& Kohls, 2001; Farrenkopf, 1992; Maslach, et 
al., 1997; Ross, et al., 1989), especially in the domain of personal accomplishment (Jayaratne, et al., 1986).

$\mathrm{H}_{0}$ : There is no statistically significant relationship between amount of supervision and high levels of burnout.

$\mathrm{H}_{\mathrm{a}}$ : There is a statistically significant relationship between amount of supervision and high level of burnout. 


\section{Chapter III Results}

This chapter will report the statistical analyses used to evaluate the hypotheses and the results of these analyses. Initial data will be summarized and the main analysis used to evaluate the study's hypotheses will be reported.

\section{Data Summary}

The independent variables used in this analysis were as follows: gender, age, level of training, years of experience working with sex offenders, therapists theoretical orientation, how often supervision is received, supervision modality, supervisor training, number of hours worked, hours worked in direct care, percentage of sex offenders on caseload, treatment modality, work setting and affect of outside stressors, as seen in more detail in Table 1. The dependent variable, burnout in therapists working with sexual abusers, is measured in three levels; high, average, or low, and is based on the results on the MBI. The level of burnout is determined by scores of three subscales of the MBI: depersonalization ( $D p)$, emotional exhaustion (EE), and a reduction of personal accomplishment (PA), which are also used as dependent variables in a secondary, ad-hoc analysis for this study. The scores for each of the sub-scales were calculated by summing up the responses given by each participant as indicated by the MBI through a statistical analysis package. If there were missing values for any of the questions, the average score for that question was used to replace the missing data. This allowed for each participant to have a score on each subscale, allowing statistical analyses to be performed on the relevant scales. Five questions comprise the depersonalization scale, nine for emotional exhaustion, and eight for personal accomplishment. The means of each sub-scale were also calculated. The means of each subscale were then compared to the standardized means of the MBI through a single sample $t$-test. This was completed to determine if the 
participants in this study were similar to the sample used to determine cut off scores of the subscales for the MBI. The results are reported below.

Table 1

Variables used in CHAID Analysis

\begin{tabular}{|c|c|c|c|}
\hline Variable & $\begin{array}{l}\text { Role of Variable } \\
\text { in CHAID Analysis }\end{array}$ & $\begin{array}{l}\text { Scale of } \\
\text { Measurement }\end{array}$ & How Measured \\
\hline Burnout & Dependent Variable & Continuous & $\begin{array}{l}\text { Based on the scores } \\
\text { of three Subscales }\end{array}$ \\
\hline Depersonalization & Dependent Variable & Continuous & $\begin{array}{l}\text { MBI Subscale } \\
5 \text { questions on MBI }\end{array}$ \\
\hline $\begin{array}{l}\text { Emotional } \\
\text { Exhaustion }\end{array}$ & Dependent Variable & Continuous & $\begin{array}{l}\text { MBI Subscale } \\
9 \text { questions on MBI }\end{array}$ \\
\hline $\begin{array}{l}\text { Personal } \\
\text { Accomplishment }\end{array}$ & Dependent Variable & Continuous & $\begin{array}{l}\text { MBI Subscale } \\
8 \text { questions on MBI }\end{array}$ \\
\hline Gender & Independent Variable & Categorical & Male or Female \\
\hline Age & Independent Variable & Continuous & $\begin{array}{l}\text { Therapist identified } \\
\text { current age }\end{array}$ \\
\hline $\begin{array}{l}\text { Level } \\
\text { of training }\end{array}$ & Independent Variable & Nominal & $\begin{array}{l}\text { Post high school } \\
\text { Degree } 3 \text { categories }\end{array}$ \\
\hline $\begin{array}{l}\text { Years of } \\
\text { experience } \\
\text { with offenders }\end{array}$ & Independent Variable & Continuous & $\begin{array}{l}\text { How many years } \\
\text { therapist worked } \\
\text { with sex offenders }\end{array}$ \\
\hline $\begin{array}{l}\text { Theoretical } \\
\text { Orientation }\end{array}$ & Independent Variable & Categorical & $\begin{array}{l}\text { Primary theoretical } \\
\text { orientation used }\end{array}$ \\
\hline $\begin{array}{l}\text { How often is } \\
\text { supervision received }\end{array}$ & Independent Variable & Continuous & $\begin{array}{l}\text { How often } \\
\text { supervision is } \\
\text { received }\end{array}$ \\
\hline $\begin{array}{l}\text { Supervision } \\
\text { Modality }\end{array}$ & Independent Variable & Categorical & $\begin{array}{l}\text { Individual, group or } \\
\text { both }\end{array}$ \\
\hline $\begin{array}{l}\text { Supervisor } \\
\text { training }\end{array}$ & Independent Variable & Categorical & $\begin{array}{l}\text { Degree, license or } \\
\text { certification }\end{array}$ \\
\hline $\begin{array}{l}\text { Hours } \\
\text { Worked }\end{array}$ & Independent Variable & Continuous & $\begin{array}{l}\text { How many hours a } \\
\text { week does therapist } \\
\text { work? }\end{array}$ \\
\hline Direct Care & Independent Variable & Continuous & $\begin{array}{l}\text { How many hours a } \\
\text { week worked in } \\
\text { direct care }\end{array}$ \\
\hline Caseload & Independent Variable & Continuous & $\begin{array}{l}\text { Percentage of sex } \\
\text { offender on caseload }\end{array}$ \\
\hline $\begin{array}{l}\text { Treatment } \\
\text { Modality }\end{array}$ & Independent Variable & Categorical & Individual or group \\
\hline
\end{tabular}




\begin{tabular}{llll}
$\begin{array}{l}\text { Work } \\
\text { Setting }\end{array}$ & Independent Variable & Categorical & $\begin{array}{l}\text { Hospital/residential } \\
\text { Prison/Correctional } \\
\text { Outpatient }\end{array}$ \\
\hline $\begin{array}{lll}\text { Outside } \\
\text { Stressors }\end{array}$ & Independent Variable & Nominal & $\begin{array}{l}\text { Yes or No } \\
\text { rated on a scale of 1- } \\
\end{array}$ \\
& & Ordinal & $\begin{array}{l}5 \text { on how outside } \\
\text { stressors affected } \\
\end{array}$ \\
& & work \\
\hline
\end{tabular}

Participants were recruited from a list of providers who are members of the Association for the Treatment of Sexual Abusers (ATSA) as well as participants in the ATSA listserv. Out of approximately 1750 members of ATSA, 210 individuals responded over a three-month period. Eight participants were excluded for failure to complete any questions on the MBI, 15 were excluded for working outside the United States, and 36 were excluded for having a caseload with less than $30 \%$ sexual offenders (one participant met two of these criteria). Therefore, the sample used for this study is $n=151$. Initially, it was determined that this study would need 200 participants to have a power of 0.80 . Using 151 participants instead of the projected 200 reduced the power of this study to 0.68 .

The majority of participants were female $(n=90)$. Current age of participants were three between the ages 18-25 (2\% of sample), 31 between the ages $26-35$ ( $20.5 \%$ of sample), 31 between the ages $36-45$ ( $20.5 \%$ of sample), 37 between the ages $46-55$ ( $24.5 \%$ of sample), and 49 participants over age 55 (32.5\% of the sample). Ninety-six percent of the participants were either masters or doctoral level therapists working with sex offenders. Seventy-six participants reported working with sex offenders for over 11 years. In reference to primary theoretical orientation, $88.7 \%$ of participants identified Cognitive Behavioral Therapy, 15.9\% psychoanalytic, 7.9\% Systems, 7.3\% Humanistic, and 1.3\% Gestalt as their primary therapeutic orientations. In reference to clinical supervision, $25.2 \%$ did not receive any supervision and out 
of 151 participants, and three did not answer this question. Of those receiving supervision, $42.5 \%$ received individual supervision, $10.6 \%$ received group supervision, and $33.1 \%$ received both individual and group supervision. Among those receiving supervision, $29.8 \%$ are supervised by a therapist with specific sex offender training, $31.1 \%$ have a state license, and $48.3 \%$ have at least a master's degree. Twenty-eight participants practiced individual therapy, 94 used group therapy and 26 used both individual and group therapy modalities when treating sex offenders (see appendix $\mathrm{C}$ for details).

Of those surveyed, $49 \%$ worked more than 40 hours per week, but on average spent less than 20 hours per week in direct client care. Of those surveyed, 114 participants indicated that $75 \%$ of their caseload is sexual offenders; 21 participants had $51 \%-75 \%$ sexual offenders on their caseload; and 16 participants list $31 \%-50 \%$ of their caseload as sexual offenders. Those who indicated $30 \%$ or less were excluded from this study in order to increase the validity of the study by insuring that the sample most closely represents the desired population (see appendix C for details).

Twenty-eight participants worked in a hospital/residential setting, while 42 participants worked in correctional/prison setting, and 85 worked in an outpatient setting. To measure the level of external stress, each participant was asked if they had to cope with any out of work stressors such as: divorce, death of a loved one, illness, birth of a child, or purchase of a new home. Only one participant indicated an inability to fulfill job requirements because of external stressors, and $51 \%$ of participants indicated that external stressors had little to no impact on their work (see appendix $\mathrm{C}$ for details). 


\section{Preliminary Analysis}

To determine if the sample obtained for this study is similar to the sample used to standardize the MBI, three different single sample $t$-tests were completed. The single sample $t$ tests were computed using the overall sample that was used for standardization of the MBI, and its sub-scales.

A single sample $t$-test was completed to compare the means of this study to the means of the overall sample (Table 2) of the MBI Human Services Survey standardization. This first single sample $t$-test indicates that the means are significantly different across all three subscales: $\mathrm{EE}\left(\mathrm{t}_{(150)}=-4.232, p<.05\right) ; \mathrm{PA}\left(\mathrm{t}_{(150)}=0.70, p<.05\right) ; \mathrm{Dp}\left(\mathrm{t}_{(150)}=-3.599, p<.05\right)$. Emotional exhaustion and depersonalization subscales have higher mean scores, and lower mean scores in personal accomplishment in the current sample, when compared to the overall MBI sample. It is important to note that the Personal Accomplishment subscale is reversed scored; lower levels of personal accomplishment indicates a potential for a higher level of burnout. This shows participants in the current sample may have a higher level of burnout than the overall sample used for standardization of the MBI.

The second single sample $t$-test was completed to compare the means of this study sample to the means of the social services subgroup sample (Table 2) of the MBI Human Services Survey. The results show that the means are significantly different for $\mathrm{EE}\left(\mathrm{t}_{(150)}=-\right.$ $4.679, p<.05), \operatorname{PA}\left(\mathrm{t}_{(150)}=4.85, p<.05\right)$, yet not significantly different for $\mathrm{Dp}\left(\mathrm{t}_{(150)}=-.236, p>.05\right)$. Emotional exhaustion and depersonalization subscales have higher mean scores and a lower mean score in personal accomplishment in the current sample when compared to the social services subgroup sample. This shows participants in the social services subgroup sample from the MBI norming study may have a higher level of burnout than the current sample. 
When compared to the mental health norming subgroup mean (Table 2) of the standardized sample of the MBI, it was found that the single sample $t$-test indicates significantly different means for PA $\left(\mathrm{t}_{(150)}=9.122, p<.05\right)$ and $\mathrm{Dp}\left(\mathrm{t}_{(150)}=4.372, p<.05\right)$, yet not for $\mathrm{EE}\left(\mathrm{t}_{(150)}=.860, p>.05\right)$. All subscales have lower mean scores in the mental health subgroup when compared to the current sample. The mental health subgroups show lower emotional exhaustion (although not significant) and lower depersonalization, as well as personal accomplishment in the mental health subgroup is higher. This shows participants in the mental health norming subgroup sample may have an overall lower level of burnout then the current sample.

Table 2 shows the subscale means and standard deviations for the overall sample used for the standardization of the MBI. It also includes the means and standard deviations for each subscale for the Social Service and Mental Health population used to standardize the MBI.

Table 3 shows the actual means and standardization of each subscale for the current study.

Table 2

MBI normative subscale means and standard deviation

\begin{tabular}{|c|c|c|c|}
\hline Sample & $\begin{array}{l}\text { Emotional } \\
\text { Exhaustion } \\
\text { M(SD) }\end{array}$ & $\begin{array}{l}\text { Personal } \\
\text { Accomplishment } \\
\mathrm{M}(\mathrm{SD})\end{array}$ & Depersonalization \\
\hline Overall MBI & $20.99(10.75)$ & $34.58(7.11)$ & $8.73(5.89)$ \\
\hline Social Service & $21.35(10.51)$ & $32.75(7.71)$ & $7.46(5.11)$ \\
\hline Mental Health & $16.89(8.9)$ & $30.87(6.37)$ & $5.72(4.62)$ \\
\hline
\end{tabular}


Table 3

Current sample subscale means and standard deviation

\begin{tabular}{llll} 
& $\begin{array}{l}\text { Emotional } \\
\text { Exhaustion }\end{array}$ & $\begin{array}{l}\text { Personal } \\
\text { Accomplishment }\end{array}$ & Depersonalization \\
Sample & M(SD) & M(SD) & M(SD) \\
\hline Current study & $17.58(9.89)$ & $34.88(5.39)$ & $7.37(4.64)$
\end{tabular}

Since the sample used for this study is not similar to the sample used to standardize the MBI or related subgroups, it was determined through personal conversation with the chairperson of this study; best practice would be to develop new cutoff scores (R. Tunick, personal communications, October 7, 2011). New cutoff scores were developed by taking onehalf standard deviation from the mean in each subgroup to identify the level of burnout for the study sample. The chart below contains the cut off scores used in this study (Table 4). Using this criteria to determine the level of burnout; this study indicated that 86 of the participants have a low burnout level, 41 have an average burnout level, and 24 have a high burnout level. Table 4

Adjusted MBI cut off scores for current sample

Burnout Dimension $\quad$ Low High

\begin{tabular}{llll}
\hline Emotional Exhaustion & $\leq 11$ & $12-22$ & $\geq 23$ \\
Personal Accomplishment & $\geq 43$ & $37-43$ & $\leq 36$ \\
Depersonalization & $\leq 4$ & $5-9$ & $\geq 10$
\end{tabular}

\section{Primary Analysis}

CHAID is a non-parametric analysis based on statistically recursive partitioning algorithms (O'Connell et al., 2006). The CHAID Technique determines the relative importance of each of the independent (predictor) variables in explaining group membership in a 
categorical dependent (outcome) variable (Tabachnick \& Fidell, 2006). This technique employs two steps. In the first, the independent variables are stratified into alternative ordinal groupings to help insure similar percentage distributions of the dependent variable among the new categories. Groups may be formed from any possible combination of the levels of an independent variable, or by placing cut-points at any values of a continuous predictor. Second, this technique utilizes $\chi^{2}$ significance levels to determine which independent variable explains the most variance in the dependent variable. This process is repeated for all significant predictor variables until obtaining significant $\chi^{2}$ values is no longer possible. The CHAID analysis controls for Overall Type I Error by keeping the alpha level at .05 for each ounique data set.

Dendrograms (i.e., classification trees) were utilized in this research to display the relative importance of statistically significant independent variables on the dependent variable. The hierarchical nature of the CHAID dendrograms provides a visual depiction of criteria and predictor variable interactions that may not otherwise be observable or detectible through traditional analytic procedures (Chan et al., 2005). The variable at the highest level of the tree is determined to have the closest statistical association with the dependent variable (O'Connell et al., 2006).

Hypotheses. The 14 independent variables used in this study were identified in previous research as variables associated with burnout. However, based on the literature review, three variables appeared to be most significant when identifying what predicts burnout; work environment, gender, and supervision. The researcher did include the 14 variables described in the literature review as this is an exploratory story and little is known about the relationship among the independent and dependent variables. The researcher must be open to unpredicted 
and unexpected results that may arise, using only the three predicted independent variables would limit the results and not provide accurate results to the studies initial question: Which variable most likely predicts burnout in therapists working with sex offenders.

Therefore, work environment, specifically prison/correctional setting, is predicted to be the most significant variable for the development of burnout. This was hypothesized as the most significant variable due to the reported high level of depersonalization found in those who work in institutional settings when compared to those who work in community settings (Clarke \& Roger, 2002; Gerstein, et al., 1987) related to regular contact with clients (Clarke \& Roger, 2007; Cherniss, 1980; Shirom, 1989) and perceived danger of working in this setting (Garland, 2002; Masters, 2004; West, 1996).

The second most influential variable was hypothesized to be gender. In past research gender has mixed results throughout historical research (Acker, 2003; Ackerly, et al., 1998; Maslach \& Jackson, 1984; Maslach \& Leiter, 2008; Pines, 1997; Shelby, et al., 2001; Shirom, 1989; \& Sprang, et al., 2007). It is hypothesized that being a female would be more likely to be related to burnout when working with sex offenders (Leiter, Frizzell, Harvie, \& Churchill, 2001). As discussed in the literature review, females are more prone to feelings of vulnerability and safety concerns (Leicht, 2008; Tyagi, 2006), generally respond more negatively to male sex offenders (Clarke \& Rogers, 2007), and experience more paranoia (Farrenkopf, 1992). Female therapists working with sex offenders have also reported higher levels of countertransference in work with incest abusers (Friedrich \& Leiper, 2006).

Supervision was the third variable that is hypothesized to be most influential to burnout level. It is hypothesized that the lower amount of supervision, the higher degree of burnout. In past studies, it had been identified that the amount of supervision and social support has 
negatively correlated to burnout (Cherniss, 1980; Clarke \& Roger, 2007; Elloy, Terpening, \& Kohls, 2001; Farrenkopf, 1992; Maslach, et al., 1997; Ross, et al., 1989), especially in the domain of personal accomplishment (Jayaratne, et al., 1986). Supervision is a key component in coping and being successful in the human service field, especially when working with more challenging populations such as sex offenders (Dillenburger, 2004; Kadambi \& Truscott, 2006).

To test this hypotheses, CHAID analyses were performed with burnout as the dependent variable and all independent variables were used, including: demographics (gender, current age), training (level of therapist training, years of experience working with sexual abusers, theoretical orientation of therapy used) and environmental work characteristics (amount of supervision, number of hours worked per week, percentage of sexual abusers as clients, individual or group therapy, and work setting). The initial CHAID analysis indicated that the type of work setting was identified as the variable most likely to predict burnout. As indicated in Figure 1, 5.7\% of those working in a hospital/residential setting have high levels of burnout, compared to $29.7 \%$ of those who work in an outpatient setting (variable 1) or in a prison/correctional setting (variable 2). These differences are significant at $p=0.000$. 
Figure 1: Classification Tree for Burnout

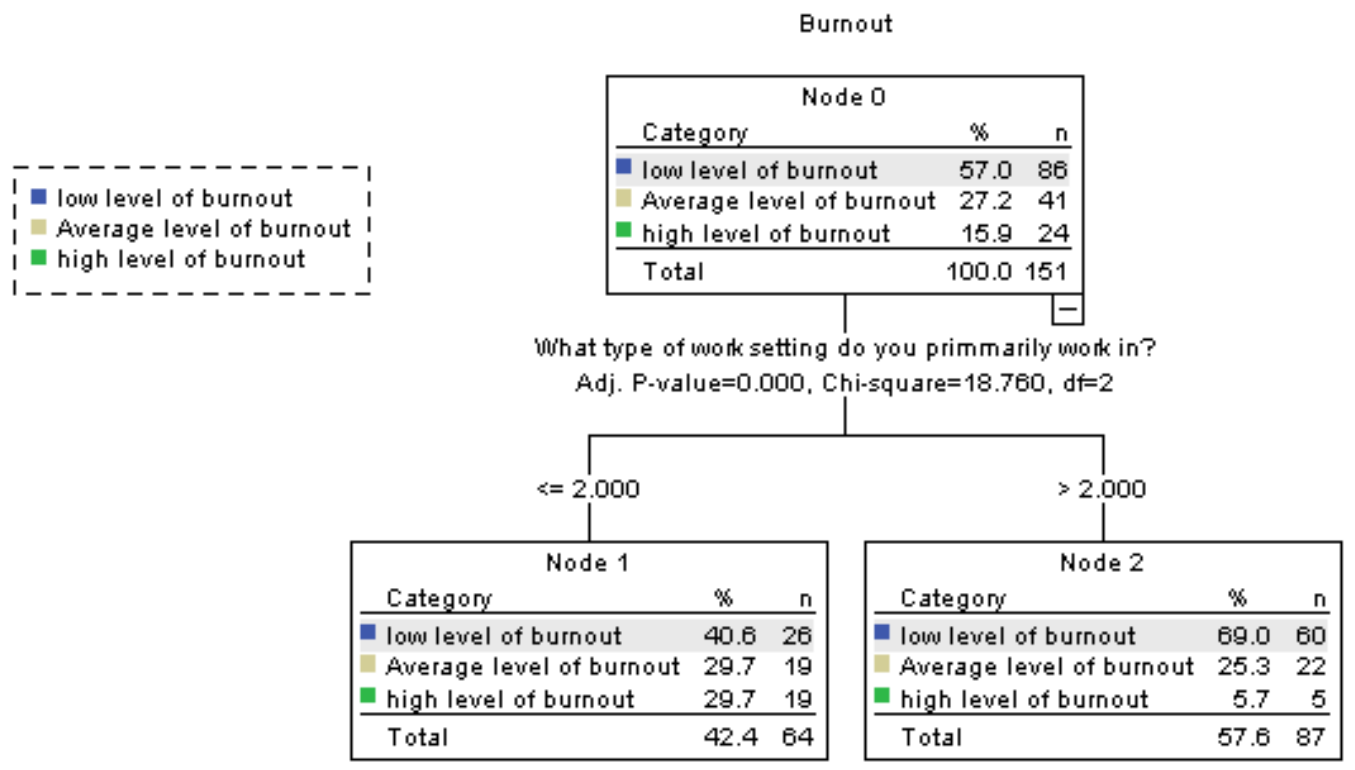

Node 1 depicts the results of the CHAID analysis identifying levels of burnout in Outpatient settings and Prison/Correctional settings. Node 2 depicts the results of the CHAID analysis identifying levels of burnout in Hospital/Residential settings.

Given that only one variable was identified as a predictor to burnout, it was decided that an examination of the three subscales of burnout might reveal more subtle relationships between aspects of burnout and the independent variables under study. Each subscale was than analyzed in order to identify which subscale variables could potentially predict burnout. All 14 variables were used in the following analyses in order maintain the openness of identifying the most significant variable that predicts burnout. These analyses found different predictor variables for each subscale. A CHAID analysis was performed with the personal accomplishment subscale of burnout as the dependent variable and all independent variables for this study, including: demographics (gender, current age), training (level of therapist training, years of experience working with sexual abusers, theoretical orientation of therapy used) and 
environmental work characteristics (amount of supervision, number of hours worked per week, percentage of sexual abusers as clients, individual or group therapy, and work setting). The CHAID found no significant predictors for Personal Accomplishment in this sample as seen in figure 2.

Figure 2: Classification Tree for Personal Accomplishment

Personal Accomplishment
\begin{tabular}{|lc|}
\hline \multicolumn{2}{|c|}{ Node 0} \\
Mean & 39.874 \\
Std. Dev. & 6.219 \\
$n$ & 151 \\
$\&$ & 100.0 \\
Predicted & 39.874 \\
\hline
\end{tabular}

A CHAID analysis was performed with emotional exhaustion, another subscale of the MBI, as the dependent variable and all dependent variables, including: demographics (gender, current age), training (level of therapist training, years of experience working with sexual abusers, theoretical orientation of therapy used) and environmental work characteristics (amount of supervision, number of hours worked per week, percentage of sexual abusers as clients, individual or group therapy, and work setting). Emotional exhaustion was predicted by the number of hours worked per week, with those working $41+$ hours (49\%) showing higher EE scores than all other categories of hours worked per week (51\%) (See figure 3). These differences are significant at $p=0.000$. 
Figure 3: Classification Tree for Emotional Exhaustion

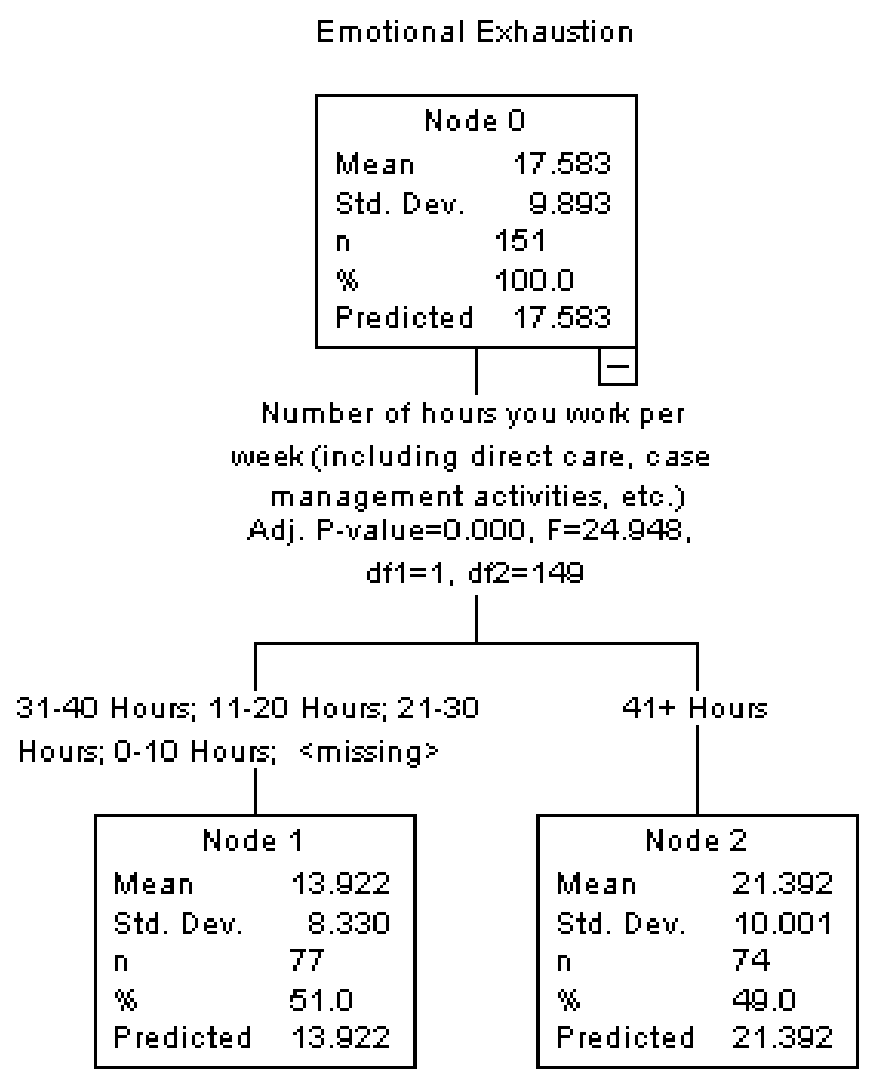

The final CHAID analysis was performed using the MBI subscale depersonalization, as the dependent variable and demographics (gender, current age), training (level of therapist training, years of experience working with sexual abusers, theoretical orientation of therapy used) and environmental work characteristics (amount of supervision, number of hours worked per week, percentage of sexual abusers as clients, individual or group therapy, and work setting) as independent variables. The CHAID analysis revealed that out of work stressors such as: divorce, death of a loved one, illness, birth of a child, etc. were the most significant predictors of burnout. Those who identified that the outside stressors had zero to minimal impact on their work and those who stated that outside stressors caused them to be unable to 
fulfill their job requirements (53\%) were more likely to have a higher level of depersonalization than those who responded at a 2, 3, or 4 on the Likert scale $(47 \%)$. These differences are significant at $p=0.000$.

Figure 4: Classification Tree for Depersonalization

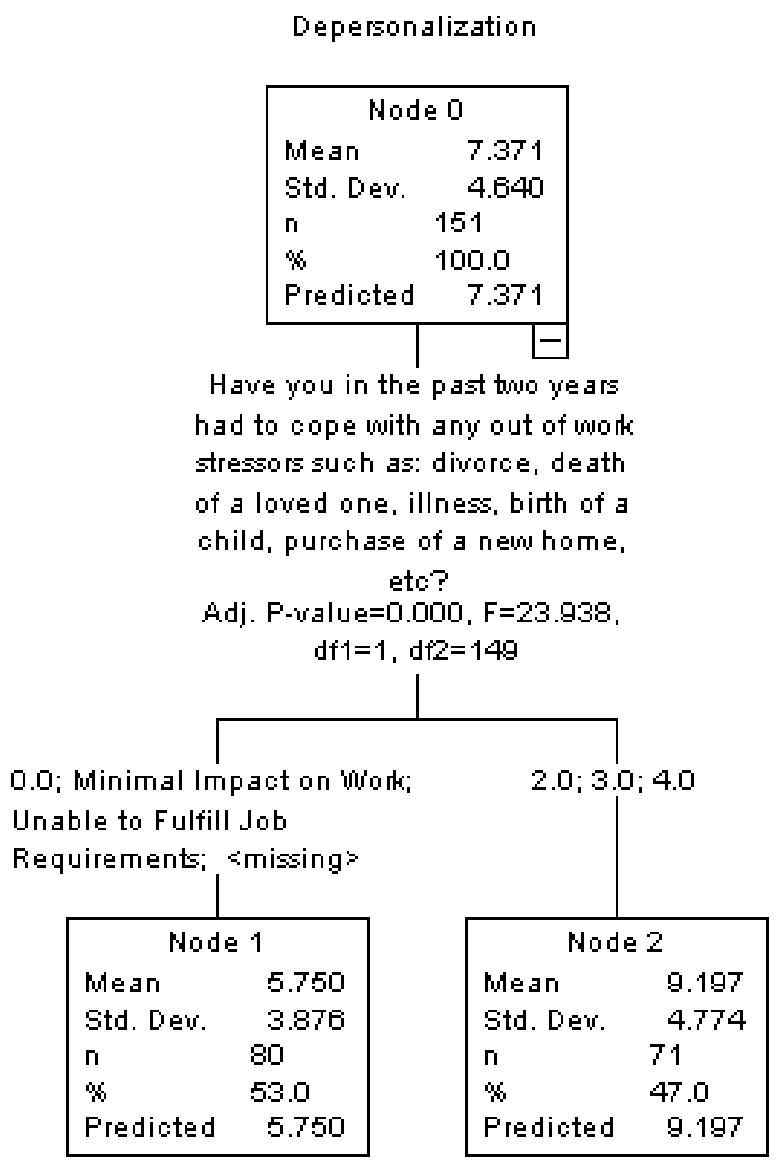

The variable considering outside stressors was rated by the participant on a Likert scale. $0=$ no impact on work, $1=$ minimal impact on work, and $5=$ Unable to fulfill job requirements.

Based upon the literature reviewed, it was hypothesized that this study would show that work environment, specifically prison/correctional setting, would be the most influential variable in predicting the development of burnout. As hypothesized, work environment was 
identified as the variable most likely to predict burnout among therapists who work with sex offenders. Although, prison/correctional settings was not the only work setting identified, it was found that outpatient settings were also predictors of high levels of burnout.

Gender was hypothesized to be the second most influential variable predicting burnout. This variable was not found to be a predictor of overall level of burnout, or any of the three subscales of burnout. The third variable that was hypothesized to be the most influential to burnout is supervision. It was hypothesized that the lower amount of supervision, the higher degree of burnout. This variable also was not found to be a predictor of overall burnout or using any of the three subscales of burnout.

Given that only work setting was found to predict overall burnout, the components of burnout were analyzed to determine if other variables could predict scores on the MBI subscales of emotional exhaustion, personal accomplishment, and depersonalization, which in turn would potentially predict burnout. It was found that working over 40 hours a week is identified as the variable most likely to predict emotional exhaustion. There are no identified variables that predict personal accomplishment. Outside stressors was found to be the most significant variable that would predict depersonalization. These implications of findings will be discussed below. 


\section{Chapter IV Discussion}

The objective of this study was to determine the variables that most predict burnout in therapists working with sex offenders. Based on the literature review, the hypothesized outcome of the study was that work environment, specifically prison and correctional settings would be the most influential variable in predicting the development of burnout. Past research has indicated that each work setting includes its own stressors, and that burnout is environmentally based (Kesler, 1990). Therapists identified has having regular contact, a client's ability to see the therapist daily, with clients (Clarke \& Roger, 2007; Cherniss, 1980; Shirom, 1989) and perceived danger (Garland, 2002; Masters, 2004; West, 1996), conflicts among staff, interactions with manipulative and resistant clients, and fear of clients in general (Shirom, 1989), are specific indicators of higher level of burnout for those who work in institutional settings. The results of this study did show that work environment is the most likely predictor of burnout. Specifically it was found that prison and correctional settings, as well as outpatient settings, functioned to predict burnout, while hospitals and residential settings were identified as the settings least likely to be associated with that condition.

The second hypothesized variable as a predictor of burnout was gender. Although past research does not show consistent results indicating gender as a variable contributing to burnout, since the clinical population comprises sex offenders, I hypothesize that gender of the clinician would likely play a role in how stress was perceived and the degree of reactivity it produces in the practitioner. Prior research indicated that a female would be more likely to experience burnout when working with sex offenders (Leiter, Frizzell, Harvie, \& Churchill, 2001) due to feelings of vulnerability and safety concerns (Leicht, 2008; Tyagi, 2006), general 
negative response to male sex offenders (Clarke \& Rogers, 2007), as well as reported higher levels of countertransference in work with perpetrators of incest (Friedrich \& Leiper, 2006). Somewhat surprisingly gender was not found to be a predictor of burnout or its subscales in this study.

Past research showed mixed results of gender being a predictor of burnout in general, and the results of this study are partially consistent with that, as women were typically identified as having higher levels of burnout similar to the findings of past research on burnout among therapists working with sex offenders. This inconsistency could have been due to different personality characteristics of women who choose to work with sex offenders. It may be that women who choose to work with sexual offenders may select this professional role for unique reasons that distinguish them from other women in mental health or from mental health workers in general, regardless of gender. It is possible that women who gravitate to such work may represent non-traditional, non-stereotypical feminine interests or personality characteristics, and this atypical profile could have disposed them to a range of distinctive reactions to the demands of work with sex offenders. Finally there may be demographics that uniquely describe women who chose to work with this client population, including some combination of age, family background, ethnicity, SES, education/training or religious/spiritual affiliations. These, and as yet unidentified, potential variables could be introduced into future studies to assess more precisely the role of gender in predicting burnout among females working with male sex offender clients. From a clinical perspective, these characteristics may be associated with the ability to feel less vulnerable, and reduce countertransference by using a healthy detachment from the issues processed in treatment. 
The third hypothesized variable as a predictor of burnout was supervision. It was predicted that a less supervision would be associated with a higher degree of burnout. Previous research identified that the amount of supervision has been negatively correlated to burnout (Cherniss, 1980; Clarke \& Roger, 2007; Elloy, Terpening, \& Kohls, 2001; Farrenkopf, 1992; Maslach, et al., 1997; Ross, et al., 1989), especially in the domain of personal accomplishment (Jayaratne, et al., 1986). In this study, supervision time was not indicated as a predictor of burnout or one of the subscales of burnout. It is noted that in this study, consultation with other professionals and involvement in professional organizations (such as ATSA) were not identified as potential forms of supervision. However, membership in a professional organizations and use of support systems outside of formal supervision, have been identified as predictors of lower levels of burnout (Clarke \& Roger, 2007; Elloy, Terpening, \& Kohls, 2001). Therefore, the finding that supervision was not predictive of burnout in this study could be due, in part, to the fact that participants were members of a professional organization, and may have been utilizing other forms of support.

Of the variables tested, only work setting, as hypothesized, was supported by the data analysis as a significant predictor of burnout. This result appears to be consistent with previous studies, which have identified the work environment as a significant predictor to burnout. The importance of this lies in the training of therapists working with sex offenders in prison/correctional settings and outpatient settings. Knowing there is a higher potential for burnout in these settings, prioritizing self-care and burnout prevention in mental health workers should be considered a vital component of training and support. Taking precautions in order to prevent burnout will reduce the number of impaired therapists working with this population, which in turn may increase the effectiveness of the treatment being provided, as well as 
reducing the negative impact associated with providing treatment to such a highly problematic clientele. Designing and delivering increased support to therapists that is aimed at identifying those at risk, thus potentially preventing the development of burnout, comprises another link in the chain leading to improved treatment outcomes. With appropriate treatment, the risk of having sex offenders in our communities is decreased, therefore providing safer environments for our families.

It was unexpected that the CHAID analysis identified only one variable to predict burnout. Therefore, a CHAID analysis was completed on each subscale of burnout to see if more subtle relationships among the variables might be found. All variables in this study were used in these analyses. The outcome of the CHAID analysis indicated no predicting variable identified for personal accomplishment subscale. The internal validity of personal accomplishment subscale of the MBI is 0.71 (Maslach, et al., 1996; Schaugeli, Enzmann, \& Girault, 1993). This lower internal validity may have played a role in not identifying a significant variable in this subscale as discussed in the limitations section as the items may represent a range of constructs not consistently perceived as related to personal accomplishment by the responders.

Another reason could be that personality characteristics were not identified as a variable in this study. To identify if personality characteristics play a role in an individual sense of personal accomplishment a qualitative research study may be more beneficial. Since research has shown that working with sex offenders is a difficult and daunting task, it would take a personality that would be more willing to do the work.

It was no surprise that the number of hours worked in a week is identified as the most significant variable as a predictor for higher levels of emotional exhaustion. Those who work 
over 40 hours a week are more likely to exhibit symptoms of emotional exhaustion. If this variable were used in studies across all occupations, it is believed that similar results would be found.

Depersonalization is the last of the three subscales analyzed. CHAID analysis indicated the variable of outside stressors would most likely predict depersonalization. Those that identified no impact, minimal impact, or unable to perform work functions as a result to outside stressors would most likely predict burnout. Social desirability is a common among self report measures. Out of 151 total participants, only one participant admitted that outside stressors caused an inability to fulfill job requirements. Seventy nine participates indicated having minimal to no impact of outside stressors on the work ability. It is difficult to imagine this to be accurate; given these are the participants whom show a higher level of depersonalization. When therapists are honest with themselves about how their personal life affects work abilities, instead of ignoring or pushing back problems, problems can be handled effectively without hardening emotionally. Depersonalization is the "unfeeling and impersonal response toward recipients of one's service, care, treatment, or instruction" (Maslach, et al., 1996, p. 4). This "unfeeling" comes from the emotional hardening of a therapist. Therefore, if the therapist is self-aware and honest about his or her personal issues, depersonalization may have played a minor role in participants' self-perceptions.

\section{Limitations of the Study.}

As described above, there are some limitations in this research should be considered when interpreting the results and making suggestions for future research. Limitations resulting from the statistical analysis and sampling procedure used in the research design are presented here. 
One limitation to this study has to do with sample size. The initial projected number of participants was 200 . This was determined by completing a power analysis with the effect size of 0.8 and an alpha level of .05 . Although initially 210 participants responded to this study, after reviewing the data and excluding those who work outside the United States, those unable to obtain a score for burnout, and with a less than $30 \%$ sex offender caseload, the total sample used for this study was 151 , leaving the statistical power at 0.68 at an alpha level of .05. This would increase the potential for Type II errors in the study.

The researcher initially sought to use the cut off values given by the MBI (Maslach Burnout Inventory) to identify the levels of burnout for each participant. Upon completing the preliminary analysis, however, it was found that the sample of this current study was not similar to the sample used to standardize the MBI. Therefore, cut off points were identified by using a half standard deviation above and below the mean in order to identify appropriate cut-off points for the sample of this study. These cut-off points have not been researched or validated to be appropriate for this population, therefore more research is needed.

Another limitation to this study was that the sample all belonged to one organization Association for the Treatment of Sexual Abusers (ATSA). Research has shown that individuals who belong to professional organizations have more access to supervision and consultation than individuals who do not belong to such an organization (Clarke \& Roger, 2007; Elloy, Terpening, \& Kohls, 2001; Farrenkopf, 1992; Maslach, et al., 1997; Ross, et al., 1989). Therefore, I was unable to determine if the variable of supervision for those who participated in this study can be generalized to all therapists who work with sex offenders.

Another sampling procedure limitation is that all the individuals who were asked to participate in this study were recruited via the Internet through a listserv. In addition, they were 
asked to use an Internet based survey program to complete the survey. Additional research may be useful in assessing all members of ATSA instead of just those who are part of the listserv. It should also be mentioned that the listserv for ATSA is sent out in two different ways.

Participants have the option of getting each individual message that is posted to the listserv or a digest version that only sends one email per day with all of the topics discussed for that day. This researcher was unable to determine how many individuals received the listserv in the digest version versus the complete version of the listserv. This may have further limited those who saw the invitation for the study. Another limitation to getting participants using the Internet is that those who work in prison or restrictive settings may have limited ability to use the Internet at work for security purposes. Therefore, may receive allowed Listservs, yet could not have the ability to reach Survey-Monkey.

Another limitation of this study involves the instruments used. The MBI is a self-report measure. Research has shown internal reliability coefficients for the three subscales at .90 for Emotional Exhaustion, .79 for Depersonalization and .71 for Personal Accomplishment with a standard error of measurement for each of 3.80, 3.16, 3.73respectively (Maslach, et al., 1996; Schaugeli, Enzmann, \& Girault, 1993). Convergent Validity has been demonstrated in three ways: (1) MBI scores are correlated with behavioral ratings from someone well acquainted with the participant therapist; (2) MBI Scores are then correlated with present job characteristics that contribute to burnout; and (3) MBI scores are further correlated with measures of different outcomes that have been hypothesized to be related to burnout (Maslach \& Jackson, 1981). The lower levels of internal reliability could have played a role in the lack of finding a significant predictor variable for personal accomplishment. There is always a concern for social desirability when completing self-report measures. The instructions for the 
MBI specifically request that the scale be presented as a survey of job related attitudes in order to not be linked to burnout and this was done also in this study to reduce social desirability as a factor in responses.

\section{Implications of Training and Practice}

Despite the above mentioned limitations, the present study has produced significant findings that will assist in the prevention of burnout among therapists working with sex offenders. As previously discussed, professional organizations such as the American Psychological Association, American Counseling Association, National Association of Social Work and Association for the Treatment of Sexual Abusers have identified the importance of reducing harm to clients and insuring professional and ethical practices. For these reasons they have developed codes of ethics mandating that therapists treat the patients they serve with the highest professional and ethical standards. The Ethical Principals of Psychology and Code of Conduct, Principal A: Beneficence and Non-maleficence (American Psychological Association, 2010) states psychologists are to be sure "to do no harm" to the clients they serve. Also, psychologists are to practice self-awareness and have knowledge of how a lack of selfawareness can potentially affect the clients served. The Professional Code of Ethics from the Association for the Treatment of Sexual Abusers (ATSA, 2001) reminds clinicians to maintain “professional judgment and objectivity” (p.3 Code 2(a)).

In order to reduce the potential of providing harm to our clients by practicing while impaired, a therapist has a responsibility to practice self-care (Barnett, et al., 2007) and the early identification of the symptoms of burnout early is important to maintain professional standards and ethical practice. Barnett, et al. (2007) stressed the importance of acknowledging that all 
therapists are vulnerable to the "pernicious effects" of the stressors and challenges faced in practice. The sooner a professional identifies symptoms of burnout, the less potential harm may be done to the client and the therapeutic relationship. Psychologists need to be aware of burnout symptoms and to identify them as soon as they present. Acknowledgement of these symptoms allows professionals to take action before any harm is done to clients, communities, or to the therapist. This acknowledgement can be achieved through self-assessments (Barnett et al., 2007, Maslach, 2003). Such assessments can be done through published works such as the MBI and Burnout Measure (BM) (Maslach \& Goldberg, 1998, Pines, 1997), or through personal evaluation of current level of stress, strain and commitments, and a self-appraisal of therapeutic performance and job satisfaction (Cherniss, 1980). Completing such assessments with staff in all work settings would assist in identifying those who may be responding to the stress of this demanding work by developing a range of undesirable symptoms.

Self-care is only one way to prevent or reduce burnout, can be accomplished in a variety of other ways, just as burnout can be experienced differently among professionals in the field. Burnout is exhibited physically and cognitively, emotionally and psychologically; as well as behaviorally. Thus, prevention and reduction of burnout can be achieved through the same means. Physical and cognitive activities that will help in prevention of burnout include maintaining positive health, getting appropriate sleep, eating balanced meals, obtaining exercise, taking walks, setting appropriate limits and goals, and avoiding drug and alcohol use (Kusker, 1990, Wicks, 2008). Emotional and psychological activities may include a reduction in negative thinking and reliance on ego-defense mechanisms (Barnett, 2007), emotional detachment, understanding and controlling personal reactions (Cherniss, 1980). Expressing emotions appropriately and identifying self stressors (Kisler, 1990), focusing on the promotion 
of self-growth and a reassessment of the importance of work (Kramen-Kahn\& Hanson 1998), as well as meditation, humor/laughter, involvement with support groups, maintaining values, spontaneity, and establishing individual boundaries (Wicks, 2008) are also emotional and psychological activities. Behavioral activities to prevent burnout include avoiding professional isolation (Barnett, 2007, Bowden, 1994, Cherniss, 1980), working on hobbies, such as gardening or scrapbooking (Wicks, 2008), attending trainings on and then practicing relaxation skills, stress inoculation, conflict resolution skills, time management skills, and learning other effective coping skills (Cherniss, 1980, Kisler, 1990, Kramen-Kahn \& Hansen, 1998, Maslach \& Goldberg, 1998). It is vital to remember that each person copes with stress differently; therefore, will need to use different strategies to prevent burnout (Bowden, 1994). The above strategies are based on an individualistic level of change. Yet, individual change is not all that is needed to prevent burnout; organizational changes will also need to be addressed (Maslach, Schaufeli, Leiter, 2001). It is important to facilitate trainings on self-care within all work settings as a way to prevent the development of burnout.

At an organizational level, some measures include trainings on issues of client motivation, interpersonal helping skills, reduction in "reality shock" (the reality of what it really means to be a therapist), restructuring the job by modifying caseloads, providing supervision and support, and using those in leadership as role models and advocates (Cherniss, 1980). It is recommended to allow colleagues to spend time together (Kramer-Kahn \& Hansen, 1998 \& Maslach, Schaufeli, Leiter, 2001), to provide case consultations (Kramer-Kahn \& Hansen, 1998), and allow for continuing education activities (Bowden, 1994, Charniss, 1980, Garland, 2002, Kramen-Kahn \& Hansen, 1998, Maslach \& Gomes, 2006). Garland (2002) focused on working in a corrections environment. He postulated that leadership would emphasize 
rehabilitation, role clarification, staff empowerment, provision of constructive feedback, balancing of caseloads, and simplification and reduction of paperwork, to name a few. I believe that these recommendations would also benefit those working in other work environments, such as outpatient settings. With effective self-care, therapists working with sex offenders will reduce the potential of developing burnout, thereby reducing the potential of practicing while impaired and thus exposing our clients, family, communities and selves to further potential harm.

\section{Recommendations for Future Research}

One variable this research project did not assess was whether involvement in professional organizations could influence therapist burnout level. Each participant in the current study belongs to ATSA and is a part of the listserv that provides members with consultation and support via the web. As discussed above, past research has indicated that support and supervision reduce burnout. I believe it would be important to determine if participation in such organizations plays a role in reducing burnout.

When comparing the means of the overall sample used to standardize the MBI to the sample used in this study, they were found to be different. The single sample $t$-test shows that the means are significantly different across all three subscales. Scores on the emotional exhaustion and depersonalization subscales derived from my sample were higher when compared to the overall MBI sample; and they had lower scores in personal accomplishment. This shows participants in the current sample may have a higher level of burnout than the sample used for standardization of the MBI. This difference may be due to other variables not considered in this study. Therefore another area of research would be to compare personality 
differences of those who work with sex offenders and those who work with the general mental health population. Qualitative research assessing personal characteristics of therapists who work with sex offenders would be able to identify if there are specific personality traits that are similar in this sample. Past research has shown that working with sex offenders is difficult work due to high recidivism rates (Pines, 2004), the potential for vicarious trauma and compassion fatigue (Barnett et al., 2007; Thorpe et al., 2001), and the slow, long-term process treatment takes (Lowe, 2001). I believe that therapists working with sex offenders may have different personality traits that could lead to them to working with sex offenders. It may be these personality traits that influence the development and level of burnout in addition to, or in conjunction with, the environmental settings identified in this study.

\section{Conclusion}

The data collected in this study indicate that work environment is the most significant predictor in burnout for therapists that work with sex offenders. Looking more closely, we saw that different variables emerged as significant when the three separate subscales of burnout were specifically analyzed. Gender was found to be the most significant predictor of personal accomplishment, number of work hours was found to be most significant in predicting emotional exhaustion, and no variable was found to be a significant predictor of depersonalization. Although much more research is needed in this area, the findings would be beneficial in the development of training programs of the different work environments for therapists working with sex offenders. The information will assist in increasing awareness of burnout which in turn may lead to the implementation of intervention and prevention strategies such as those described previously. The work therapists do with sex offenders is extremely 
difficult and the potential for burnout is high. The work these therapists perform is vitally important as their work directly impacts the safety of the world in which we live. Burnout prevention will increase therapists' capacities for healthy functioning, as there will be a decrease in therapist impairment. This in turn will decrease the risk of harm to our communities and to ourselves. 


\section{References}

Acker, G. M. (2003). Role conflict and ambiguity: Do they predict burnout among mental health workers. Social Work in Mental Health, 3, 63-80.

Ackerly, G. D., Burnell, J., Holder, D. C., \& Kurdek, L. A. (1988). Burnout among licensed psychologists. Professional Psychology: Research and Practices, 19(6), 624-631.

American Psychological Association (2010). Ethical principles of psychologists and code of conduct. Washington DC: American Psychological Association. Retrieved from http://www.apa.org.

Arthur, N. M. (2001). The assessment of burnout: A review of three inventories useful for research and counseling. Journal of Counseling and Development, 69, 186-189.

Association for the Treatment of Sexual Abusers (2001). Association for the Treatment of Sexual Abusers professional code of ethics. Beaverton, OR: Association for the Treatment of Sexual Abusers.

Barnett, J.E., Baker, E.K., Elman, N.S., \& Schoener, G. R. (2007). In pursuit of wellness: The self-care imperative. Professional Psychology: Research and Practice, 38(6), 603-612.

Belcastro, P.A., Gold, R. S., \& Grant, J. (1982). Stress and burnout: Physiologic effects on correctional teachers. Criminal Justice and Behavior, 9(4). 387-395.

Blanchard, G.T. (1998). The difficult connection: The therapeutic relationship in sex abuser treatment. Brandon, VT: Safer Society Press.

Bowden, G. (1994). Work stress, burnout and coping: A review and an empirical study of staff in supported housing. Clinical Psychology and Psychotherapy, 1(4), 219-232. 
Burisch, M. (1993). In search of theory: Some ruminations on the nature and etiology of burnout. In W. B. Schaufeli, C. Maslach, T. Marech, (eds.) Profession burnout: Recent developments in theory and research (pp.75-93). New York: Taylor \& Francis.

Chan, F., Wong, D. W., Rosenthal, D. A., Kundu, M. M., Dutta, A. (2005). Eligibility rates of traditionally underserved individuals with disabilities revisited: A data mining approach. Journal of Applied Rehabilitation Counseling, 36(3), 3-10.

Cherniss, C. (1980). Reducing professional burnout: The role of training. Professional burnout in human service organizations. New York, NY: Praeger Publishers.

Cherniss, C. (1992). Long-term consequences of burnout: An exploratory study. Journal of Organizational Behavior, 13, 1-11.

Cherniss, C. (1993). Role of professional self-efficacy in the etiology and amelioration of burnout. In W. B. Schaufeli, C. Maslach, T. Marech, (eds.) Profession burnout: Recent developments in theory and research (pp.135-149). New York: Taylor \& Francis.

Clarke, J. \& Roger, D. (2002). Working therapeutically with sex offenders: The potential impact on the psychological well-being of treatment providers. Issues in Forensic Psychology, 1, 82-96.

Clarke, J. \& Roger D. (2007). The construction and validation of a scale to assess psychological risk and well-being in sex offender treatment providers. The British Psychological Society, 12, 83-100.

Cordes, C.L \& Dougherty, T. W. (1993). A review and an integration of research on job burnout. Academy of Management Review, 18(4), 621-656.

Cox, T., Kuk, G., \& Leiter, M. P. (1993). Burnout, health, work stress, and organizational healthiness. In W. B. Schaufeli, C. Maslach, T. Marech, (eds.) Profession burnout: 
Recent developments in theory and research (pp.177-193). New York: Taylor \& Francis.

Craig, L. A., Browne, K. D., \& Stringer, I. (2003). Treatment and sexual offence recidivism. Trauma, Violence, and Abuse, 4(1), 70-89.

Devilly, G.J., Wright, R., \& Varker, T. (2009). Vicarious trauma, secondary traumatic stress or simply burnout? Effect of trauma therapy on mental health professionals. Australian and New Zealand Journal of Psychiatry, 43, 373-385.

Dillenburger, K. (2004). Causes and alleviation of occupational stress in child care work. Child Care in Practice, 10(3), 213-224.

Edelwich, J. (1980). Burn-out: Stages of disillusionment in the helping professions. New York: Human Sciences Press.

Elliot, T. R., Shewchuk, R., Hagglund, K., Rybarczyk, B., Harkins, S. (1996). Occupational burnout, tolerance for stress, and coping among nurses in rehabilitation units. Rehabilitation Psychology, 41(4), 267-284.

Elloy, D. F., Terpening, W., \& Kohls, J. (2001). A causal model of burnout among selfmanaged work team members. The Journal of Psychology, 135(3), 321-334.

Emerson, S., \& Markos, P. A. (1996). Signs and symptoms of an impaired counselor. Journal of Humanistic Education and Development, 34(3), 108-118.

Ennis, L. \& Horne, S. (2003). Predicting psychological distress in sex offender therapists. Sexual Abuse: A Journal of Research and Treatment, 15(2), 149-157.

Enzmann D. (2005). Burnout and emotions: an under researched issue in search of a theory. In A. S. Antoniou, and C. L. Cooper, (Eds.), Research companion to organizational health psychology (pp. 495-502). Northampton, MA: New Horizons in Management. 
Etzion, D., \& Pines, A. (1986). Sex and culture in burnout and coping among human service professionals: A social psychological perspective. Journal of Cross-Cultural Psychology, 17(2), 191-209.

Farber, B. A., \& Heigetz, L. J. (1982). The process and dimensions of burnout in psychotherapists. Professional Psychology, 13(2), 293-301.

Farrenkopf, T. (1992). What happens to therapists who work with sex abusers? Journal of Abuser Rehabilitation, 18(3/4), 217-223.

Field, A. (2005). Discovering Statistics Using SPSS ( $2^{\text {nd }}$ ed.). Thousand Oaks, CA: Sage Publications.

Friedrich, M. \& Leiper, R. (2006). Countertransference reactions in therapeutic work with incestuous sexual abusers. Journal of Child Sexual Abuse, 15(1), 51-68.

Freudenberger, H. J. (1974). Staff burn-out. Journal of Social Issues, 30(1), 159-165.

Freudenberger, H. J. (1975). The staff bur-out syndrome in alternative institutions. Psychotherapy: Theory, Research and Practice, 12(1). 73-82.

Gabassi, P. G., Cervai, S., Rozbowsky, P., Semeraro, A., \& Gregori, D. (2002). Burnout syndrome in the helping professions. Psychological Report, 90, 309-314.

Garland, B. (2002). Prison treatment staff burnout: Consequences, Causes and prevention. Corrections Today, 116-121.

Garland, B. (2004). The impact of administrative support on prison treatment staff burnout: an exploratory study. The Prison Journal, 48(1), 452-471.

Garman, A.N., Corrigan, P.W., \& Morris, S. (2002). Staff burnout and patient satisfaction: Evidence of relationships at the care unit level. Journal of Occupational Health Psychology, 7(3), 235-241. 
Gerstein, L. H., Topp, C. G., \& Correll, G. Y. (1987). The role of the environment and person when predicting burnout among correctional personnel. Criminal Justice and Behavior, $14(3), 352-369$.

Golembiewski, R. T. \& Munzenrider, R. F. (1988). Phases of Burnout: Developments in concepts and applications. New York, NY: Praeger Publishers.

Greenglass, E. R. (2005). Proactive coping, resources, and burnout: Implications for occupational stress. In A-S. Antoniou, \& C.L. Cooper, (Eds.), Research companion to organizational health psychology (pp. 503-515). Northampton, MA: New Horizons in Management.

Grosch, W. N. \& Olsen, D. C. (1994). When Helping Starts to Hurt: A new look at burnout among psychotherapists. New York, NY: W.W. Norton \& Company, Inc.

Halbesleben, J. R. B. \& Buckley, M. R. (2004). Burnout in organizational life. Journal of Management, 30(6), 859-879.

Hallsten, L. (1993). Burning out: A framework. In W. B. Schaufeli, C. Maslach, T. Marech, (eds.) Profession burnout: Recent developments in theory and research (pp.95-113). New York: Taylor \& Francis.

Hobfoll, S. E., \& Freedy, J. (1993). Conservation of resources: A general stress theory applied to burnout. In W. B. Schaufeli, C. Maslach, T. Marech, (eds.) Profession burnout: Recent developments in theory and research (pp.115-129). New York: Taylor \& Francis.

Hyphantis, T. \& Mavreas, V. (2005). 'Burning in' - 'burning out' in public: aspects of the burnout process in community-based psychiatric services. In A-S. Antoniou, \& C.L. 
Cooper, (Eds.), Research companion to organizational health psychology (pp. 537-543).

Northampton, MA: New Horizons in Management.

Jayaratne, S., Chess, W. A., \& Kinkel, D. A. (1986). Burnout: Its impact on child welfare workers and their spouses. Social Work, 31(1), 53-58.

Kadambi, M. \& Truscott, D. (2006). Concept mapping professionals' perceptions of reward and motive in providing sex offender treatment. Journal of Offender Rehabilitation, 42(4), 37-58.

Kahill, S. (1988). Symptoms of professional burnout: A review of the empirical evidence. Canadian Psychology, 29(3), 284-297.

Kaplowitz, M. D., Hadlock, T. D., \& Levine, R. (2004). A comparison of web and mail survey response rates. Public Opinion Quarterly, 68(1), 94-101.

Kesler, K. D. (1990). Burnout: A multimodal approach to assessment and resolution. Elementary School Guidance and Counseling, 24(4), 303-312.

Koeske, G. F., \& Koeske, R.D. (1989). Work load and burnout: Can social support and perceived accomplishment help? Social Work, 243-248.

Kottler, J., \& Hazler, R. J. (1996). Impaired counselors: The dark side of brought into light. Journal of Humanistic Education and Development, 34, 98-107.

Kramen-Kahn, B. \& Hansen, N. D. (1998). Rafting the rapids: Occupational hazards, rewards, and coping strategies of psychotherapists. Professional Psychology: Research and Practice, 29(2), 130-134.

Kraus, V. I. (2005). Relationship between self-care and compassion satisfaction, compassion fatigue, and burnout among mental health professionals working with adolescent sex offenders. Counseling and Clinical Psychology Journal, 2(1), 81-88. 
Lee, R. T. \& Ashforth, B. E. (1990). On the meaning of Maslach's three dimensions of burnout. Journal of Applied Psychology, 75(6), 743-747.

Leicht, S. K. C. (2008). The impact on professionals of working with sex offenders. In J. Houston \& S Galloway (Eds.), Sexual offending and mental health: Multidisciplinary management in the community. (pp.263-279). Philadelphia, PA: Jessica Kingsley Publishers.

Leiter, M. P. (1993). Burnout as a developmental process: Consideration of models. In W. B. Schaufeli, C. Maslach, \& T. Marek's (Eds.), Professional burnout: Recent developments in theory and research, (pp. 237-250).

Leiter, M. P., Frizzell, C., Harvie, P., \& Churchill, L. (2001). Abusive interactions and burnout: Examining occupation, gender, and the mediating role of community. Psychology and Health, 16, 547-563.

Leiter, M. P., \& Maslach, C. (2005). A mediation model of job burnout. In A-S. Antoniou, \& C.L. Cooper. (Eds.), Research companion to organizational health psychology, (pp. 544-564). Northampton, MA: New Horizons in Management.

Linley, P. A., \& Joseph, S. (2007). Therapy work and therapists' positive and negative wellbeing. Journal of Social and Clinical Psychology, 26(3), 385-403.

Lowe, G. (2001). Program development: Key elements and staff management. Handbook for sexual abuser assessment and treatment, (pp.37-46). Brandon, VT: Safer Society Press.

Marshall, W. L. \& Serran, G. A. (2004). The role of the therapist in offender treatment. Psychology, Crime and Law, 10(3), 309-320.

Maslach, C. (1982). Burnout-The cost of caring. Englewood Cliffs, NJ: Prentice-Hall, Inc. 
Maslach, C. (1986). Stress, burnout, and workaholism. In R.R. Kilburg, P.E. Nathan, \& R.W. Thoreson (Eds.), Professionals in distress; issues, syndromes, and solutions in psychology (p. 53-75). Washington DC: American Psychological Association.

Maslach, C. (1993). Burnout: A multidimensional perspective. In W. B. Schaufili, C. Maslach, \& T. Marek (eds). Professional Burnout: Recent developments in theory and research (pp. 19-32). Philadelphia, PA: Taylor \& Francis.

Maslach, C. (2001). What have we learned about burnout and health? Psychology and Health, 16, 607-611.

Maslach, C. \& Goldberg, J. (1998). Prevention of burnout: New perspectives. Applied and Preventative Psychology, 7, 63-74.

Maslach, C. \& Gomes, M. E. (2006). Overcoming Burnout. In R. M. MacNair (Ed.), Working for peace: A handbook of practical psychology and other tools, (pp.43-49).

Maslach, C. \& Jackson, S. E. (1981). The measurement of experienced burnout. Journal of Occupational Behavior, 2, 99-113.

Maslach, C. \& Jackson, S.E. (1984). Burnout in organizational settings. In S. Oskamp (ed). Applied social psychology annual (pp. 133-153). Beverly Hills, CA: Sage Publications.

Maslach, C., Jackson, S. E., \& Leiter, M. P. (1996). Maslach burnout inventory manual (3 ${ }^{\text {rd }}$ ed.). Mountain View, CA: CPP Inc. 
Maslach, C., Jackson, S. E., \& Leiter, M. P. (1997). Maslach burnout inventory manual (3 ${ }^{\text {rd }}$ ed.). In C. Zalaquett \& R. J. Wood, (eds), Evaluating stress: A book of resources (pp. 191-218). Lanham, MD: The Scarecrow Press, Inc.

Maslach, C., \& Leiter, M. P. (2008). Early predictors of job burnout and engagement. Journal of Applied Psychology, 93(3), 498-512.

Maslach, C., Schaufeli, W.B., \& Leiter, M.P. (2001). Job Burnout. Annual Review of Psychology, 52, 397-422.

Masters, R. E. (2004). Counseling criminal justice offenders $\left(2^{\text {nd }}\right.$ ed.). Thousand Oaks, CA: Sage Publications.

Miller, K. I., Stiff, J. B. \& Ellis, B. H. (1988). Communication and empathy as precursors to burnout among human service workers. Communication Monographs, 55, 250-265.

Nelson, M., Herlihy, B., \& Oescher, J. (2002). A survey of counselor attitudes towards sex offenders. Journal of Mental Health Counseling, 24(1), 51-67.

Noworol, C., Zarczynski, Z., Fafrowicz, M., \& Marek, T. (1993). Impact of professional burnout on creativity and innovation. In W. B, Schaufeli, C. Maslach, \& T. Marech, (eds.) Professional burnout: Recent developments in theory and research (pp.164-175). Philadelphia, PA: Taylor \& Francis.

O’Connell, J., Novins, D. K., Beals, J., Croy, C., Baron, A. E., Spicer, P., Buchwalk, D., \& the American Indian Service Utilization, Psychiatric Epidemiology, Risk and Protective Factors Project Team (2006). The relationship between patterns of alcohol use and 
mental and physical health disorders in two American Indian populations. Addiction, 101, 69-83.

Patten, M. L. (2007). Understanding research methods: An overview of essential, $6^{\text {th }}$ edition. Glendale, CA: Pyiczak Publishing.

Peiro, J. M., Gonzalex-Roma, V., Tordera, N., \& Manas, M. A. (2001). Does roles stress predict burnout over time among health care professionals? Psychology and Health, 16, $511-525$.

Pines, A. M. (1997). Gender differences in burnout: Israelis' responses to the intifada. European Psychologist, 2, (1), 28-34.

Pines, A. M. (2005b). Unconscious influences on the choice of a career and their relationship to burnout: a psychoanalytic existential approach. In A-S. Antoniou \& C. L. Cooper, (Eds.), Research companion to organizational health psychology, (pp. 579-598).

Northampton, MA: New Horizons in Management.

Pines, A. M. \& Keinan, G. (2005). Stress and burnout: The significant difference. Personality and Individual Differences, 39, 625-635.

Pines, A. \& Maslach, C. (1978). Characteristics of staff burnout in mental health settings. Hospital and Community Psychiatry, 29(4), 233-237.

Ross, R. R., Altmaier, E. M., \& Russell, D. W. (1989). Job stress, social support and burnout among counseling center staff. Journal of Counseling Psychology, 36(4), 464-470.

Samenow, S. E. (2004). Inside the criminal mind (revised and updated ed.). New York, NY: Crown Publishers. 
Sanghara, K.K., \& Wilson, J. C. (2006). Stereotypes and attitudes about child sexual abusers: A comparison of experienced and inexperienced professionals in sex offender treatment. Legal and Criminological Psychology, 11, 229-244.

Savicki, V., \& Cooley, E. J. (1982). Implications of burnout research and theory for counselor educators. Personnel and Guidance Journal, 60(7), 415-419.

Schaufeli, W.B, Bakker, A.B., Hoogduin, K., Schaap, C. \& Kladler, A. (2001). On the clinical validity of the Maslach burnout inventory and the burnout measure. Psychology and Health, 16,565-582.

Schaufeli, W.B., Enzmann, D., \& Girault, N. (1993). Measurement of burnout: A review. In W. B. Schaufili, C. Maslach, \& T. Marek (eds). Professional burnout: Recent developments in theory and research (pp. 199-215). Philadelphia, PA: Taylor \& Francis.

Schaufeli, W. B., van Dierendonck, D., \& van Gorp, K. (1996). Burnout and reciprocity: Towards a dual-level social exchange model. Work and Stress, 10(3), 225-237.

Sheehan, K. (2001). E-mailed survey response rates: A review. Retrieved from http://jcmc.indiana.edu/vol16/issue2/sheehan.html.

Shelby, R. A., Stoddart, R. M., \& Taylor, K. L. (2001). Factors contributing to levels of burnout among sex abuser treatment providers. Journal of Interpersonal Violence, $16(11), 1205-1217$.

Shirom, A. (1989). Burnout in work organization. In C. L. Cooper \& I. Robertson (eds.) International review of industrial and organizational psychology, (pp. 25-48). John Wiley \& Sons Ltd. 
Shirom, A., \& Ezrachi, Y. (2003). On the discriminant validity of burnout, depression and anxiety: A re-examination of the burnout measure. Anxiety, Stress, and Coping, 16, (1), 83-97.

Skorupa, J. \& Agresti, A. A. (1993). Ethical beliefs about burnout and continued professional practice. Professional Psychology: Research and Practice, 24(3). 281-285.

Sprang, G., Clark, J. J. \& Whitt-Woosley, A. (2007). Compassion fatigue, compassion satisfaction, and burnout: Factors impacting a professional's quality of life. Journal of Loss and Trauma, 12, 259-280.

Strasburger, L. H. (2001). The treatment of antisocial syndromes: The therapist's feelings. The mark of Cain: Psychoanalytic insight and the psychopath, 297-313.

Tabachnick, B. G., \& Fidell, L. S. (2006). Using multivariate statistics, 5th ed. Boston: Allyn and Bacon, 709-796.

Thorpe, G. L. (2001). Brief Report: Dimensions of burnout in professionals working with sex abusers. Sexual Abuse: A Journal of Research and Treatment, 13(3), 197-203.

Thorpe, G. L., Rightland, S., \& Kubik, E. K. (2001). Brief report: Dimensions of burnout in professionals working with sex offenders. Sexual Abuse: A Journal of Research and Treatment, 13(3), 197-203.

Tyagi, S. V. (2006). Female counselors and male perpetrators of violence against women. Woman and Therapy, 29(1/2), 1-22.

Way, I., VanDeusen, K., \& Cottrell, T. (2009). Vicarious Trauma: Predictors of clinicians’ disrupted cognitions about self-esteem and self-intimacy. Journal of Child Sexual Abuse, 16(4), 81-98. 
Welte, Barnes, Weiczoreck \& Tidwell (2004). Gambling participation and pathology in the United States - A socio-demographic analysis using classification trees. Addictive Behaviors, 29, 983-989.

West, A. (1996). The risks of burnout. In C. Cordess, \& M. Cox, (eds.) Forensic psychotherapy: Crime, psychodynamics and the offender patient (Vol. 2). Bristol, PA: Jessica Kindsley Publishers.

Westman, M. \& Etzion, D. (2001). The impact of vacation and job stress on burnout and absenteeism. Psychology and Health, 16, 595-606.

Wicks, R. (2008). The resilient clinician. New York, NY: Oxford University Press.

Zapf, D., Seifert, C., Schmutte, B., Mertini, H., \& Holtz, M. (2001). Emotion work and job stressors and their effects on burnout. Psychology and Health, 16, 527-545. 
Appendix A 


\section{Dear Participant,}

This letter is a request for you to take part in a research project to identify variables that limit therapist effectiveness in working with sex offenders. This project is being conducted by Jennifer Lytle, M.Ed. with supervision of Dr. Roy Tunick, Faculty of Counseling, Counseling Psychology and Rehabilitation Counseling in the College of Human Resources and Education at West Virginia University, for a Ph.D. in Counseling Psychology. Your participation in this project is greatly appreciated and will take approximately 15 minutes to complete this questionnaire. The questionnaire is available through SurveyMonkey, a secure and confidential website. You can participate in this study by clicking on this link http://www.surveymonkey.com/s/CTMW3GH . Please read the complete directions prior to completing the survey.

This study has been reviewed by the ATSA Research Committee who determined that it meets the criteria necessary for access to the list-serve: namely, a) the topic is of interest and relevance to ATSA membership, b) the list-serve is an appropriate method of recruiting participants, and c) the project has been approved by a recognized research ethics review board. Permission to use the ATSA list-serve to recruit participants does not imply that ATSA endorses or approves of the theory, hypotheses, or methods of this study.

If you decide to participate, the completed questionnaire will be seen as you providing consent to participate in this study. Your involvement in this project will be kept as confidential as legally possible. All data will be reported in the aggregate. Your participation is completely voluntary. You do not need to answer all of the questions and may quit the study at any time.

In the event you experience any side effects or injury related to this research, contact Dr. Roy Tunick at (304) 293-2172. If you have any questions, concerns, or complaints about this research, please contact Jennifer Lytle at (724) 880-4456 or Dr. Tunick at (304) 293-2172.

For information regarding your rights as a research subject, to discuss problems, concerns, or suggestions related to the research, to obtain information or offer input about the research, contact the Office of Research Compliance at (304) 293-7073. West Virginia University's Institutional Review Board (IRB) has acknowledgment of this study on file.

I hope that you will participate in this research project, as it could be beneficial in understanding the impact of therapists' self care on treatment effectiveness in working with sex offenders. Thank you very much for your time. Should you have any questions about this letter or the research project, please feel free to contact Jennifer Lytle at (724) 880-4456 or by e-mail at jlytle1@ mix.wvu.edu. Thank you for considering my study worthy of your time, effort and participation.

Sincerely, Jennifer Lytle

Doctoral Candidate

West Virginia University 
Appendix B 
On the following pages, there are 15 questions about you and your work. Place a mark by the answer that best fits your situation. If the question has more than one answer, check all that apply.

1. Where do you work?

○ United States

o Other:

2. Gender
- Male
○ Female

3. Current age

○ $18-25$

○ 26-35

○ $36-45$

○ $46-55$

○ $55+$

4. Level of training

- Bachelors degree

- Masters degree

- Doctoral degree

5. Years working with sex offenders
$0<2$ years
○ 2-5 years
○ 6-10 years
○ $11+$

6. Primary theoretical orientation

- Psychoanalytic/psychoanalysis therapy/psychodynamic

o Systems therapy

- Gestalt therapy

- Cognitive behavioral therapy

- Humanistic/existential
7. How often do you receive clinical supervision?

○ Not at all

0 < once a month

- Once a month

- 2-3 times a month

o Once a week

o > once a week

8. What type of supervision modality do you receive?

○ Individual supervision

- Group supervision

$\circ$ Both individual and group supervision

9. Supervisor's training (Check all that apply)
- Master Degree
- Doctorate degree
- State license
- Specific sex offender training
o other

10. Number of hours you work per week (including direct care, case management activities, etc.)
○ 0-10 hours
- 11-20 hours
○ 21-30 hours
○ 31-40 hours
- 41+ hours 
11. Number of hours per week in direct client care
○ $0-10$ hours
- 11-20 hours
- 21-30 hours
- 31-40 hours
○ 41+ hours

12. Percentage of caseload that is sex offenders
$0<10 \%$
○ $11 \%-30 \%$
○ $31 \%-50 \%$
○ $51 \%-75 \%$
○ $76 \%+$

13. Which treatment modality due you primarily use?
- Individual
○ Group

14. What type of work setting do you primarily work in?
- Hospital/residential setting
- Prison/correctional setting
○ Outpatient setting

15. Have you in the past two years had to cope with any out of work stressors such as: divorce, death of a loved one, illness, birth of a child, purchase of a new home, etc?
- Yes
○ No

If yes, rate how these events affected your work ( $1=$ minimal impact on work: $5=$ unable to fulfill job requirements)

$\begin{array}{lllll}1 & 2 & 3 & 4 & 5\end{array}$


Appendix C 


\begin{tabular}{|c|c|c|c|c|}
\hline Variable & Descriptor & Low level of Burnout & Average level of burnout & High level of burnout \\
\hline \multirow[t]{2}{*}{ Gender } & Male & 31 & 16 & 5 \\
\hline & Female & 49 & 18 & 13 \\
\hline \multirow{5}{*}{ Current Age } & $18-25$ & 1 & 0 & 1 \\
\hline & $26-35$ & 14 & 8 & 5 \\
\hline & $36-45$ & 18 & 6 & 5 \\
\hline & $46-55$ & 17 & 10 & 2 \\
\hline & $>55$ & 30 & 10 & 5 \\
\hline \multirow[t]{3}{*}{ Level of training } & Bachelors Degree & 2 & 0 & 2 \\
\hline & Masters Degree & 63 & 25 & 12 \\
\hline & Doctoral Degree & 14 & 9 & 4 \\
\hline \multirow[t]{4}{*}{ Years working with sex offenders } & $<2$ & 10 & 2 & 2 \\
\hline & $2-5$ years & 11 & 4 & 7 \\
\hline & $6-10$ years & 18 & 8 & 5 \\
\hline & $11+$ years & 40 & 20 & 4 \\
\hline \multirow[t]{5}{*}{ Modality of therapy } & Psychoanalytic & 12 & 6 & 3 \\
\hline & Systems & 4 & 2 & 3 \\
\hline & Gestalt & 1 & 1 & 0 \\
\hline & CBT & 72 & 29 & 16 \\
\hline & Humanistic & 7 & 3 & 0 \\
\hline \multirow[t]{6}{*}{ Receiving clinical supervision } & Not at all & 25 & 9 & 0 \\
\hline & $<$ once a month & 11 & 4 & 2 \\
\hline & Once a month & 11 & 3 & 2 \\
\hline & $2-3$ times a month & 13 & 12 & 2 \\
\hline & Once a month & 14 & 3 & 7 \\
\hline & >once a month & 6 & 1 & 5 \\
\hline \multirow[t]{3}{*}{ Supervision modality } & Individual & 25 & 12 & 4 \\
\hline & Group & 8 & 2 & 4 \\
\hline & Both & 23 & 11 & 10 \\
\hline \multirow[t]{4}{*}{ Supervisor Training } & Masters Degree & 40 & 11 & 9 \\
\hline & Doctoral Degree & 21 & 14 & 11 \\
\hline & State license & 29 & 8 & 6 \\
\hline & Sex offender specific & 28 & 6 & 5 \\
\hline \multirow[t]{3}{*}{ Number of hours worked per week } & $0-10$ hours & 5 & 2 & 0 \\
\hline & $11-20$ hours & 6 & 1 & 0 \\
\hline & 21-30 hours & 12 & 2 & 0 \\
\hline
\end{tabular}




\begin{tabular}{|c|c|c|c|c|}
\hline & $31-40$ hours & 28 & 9 & 4 \\
\hline & $41+$ hours & 28 & 20 & 14 \\
\hline \multirow{5}{*}{ Number of hours in direct care } & 0 -10 hours & 14 & 6 & 1 \\
\hline & $11-20$ hours & 33 & 13 & 10 \\
\hline & $21-30$ hours & 27 & 13 & 3 \\
\hline & $31-40$ hours & 5 & 1 & 4 \\
\hline & $41+$ hours & 1 & 1 & 0 \\
\hline \multirow[t]{3}{*}{ Percentage of caseload sex offender } & $31 \%-50 \%$ & 10 & 5 & 0 \\
\hline & $51 \%-75 \%$ & 13 & 3 & 2 \\
\hline & $>75 \%$ & 57 & 26 & 16 \\
\hline \multirow[t]{3}{*}{ Treatment Modality } & Individual & 14 & 6 & 4 \\
\hline & Group & 50 & 20 & 12 \\
\hline & Both & 16 & 7 & 1 \\
\hline \multirow[t]{3}{*}{ Work Setting } & Hospital/Residential & 6 & 7 & 7 \\
\hline & Corrections/Prison & 17 & 8 & 8 \\
\hline & Outpatient & 53 & 19 & 2 \\
\hline \multirow[t]{6}{*}{ Outside Stressors (Likert scale 0-5) } & 0-No impact & 20 & 13 & 1 \\
\hline & 1-Minimal impact & 27 & 5 & 3 \\
\hline & 2 & 21 & 11 & 5 \\
\hline & 3 & 7 & 3 & 7 \\
\hline & 4 & 2 & 2 & 2 \\
\hline & $\begin{array}{l}5 \text {-Unable to fulfill job } \\
\text { requirements }\end{array}$ & 1 & 0 & 0 \\
\hline
\end{tabular}

